\title{
A multi-criteria decision framework to support measurement-system design for bridge load testing
}

\author{
Numa J. Bertola ${ }^{1,2}$ \\ Marco Cinelli ${ }^{3}$ \\ Simon Casset ${ }^{1,2}$ \\ Salvatore Corrente ${ }^{4}$ \\ Ian F.C. Smith ${ }^{1,2}$
}

\begin{abstract}
Due to conservative design models and safe construction practices, infrastructure usually has unknown amounts of reserve capacity that exceed code requirements. Quantification of this reserve capacity has the potential to lead to better asset-management decisions by avoiding unnecessary replacement and by lowering maintenance expenses. However, such quantification is challenging due to systematic uncertainties that are present in typical structural models. Field measurements, collected during load tests, combined with good structural-identification methodologies may improve the accuracy of model predictions. In most structural-identification tasks, engineers usually select and place sensors based on experience and high signal-to-noise estimations. Since the success of structural identification depends on the measurement system, research into measurement system design has been carried out over several decades. Despite the multi-criteria nature of the problem, most researchers have focused only on the information gained by the measurement system. This study presents a framework to evaluate and rank possible measurement-system designs based on a tiered multi-criteria strategy. Performance criteria for the design of measurement systems include monitoring costs, information gain, ability to detect outliers and impact of loss of information in case of sensor failure. Through including conflicting criteria, such as cost of monitoring and information gain, the optimal measuring system becomes a Pareto-like choice that ultimately depends on asset-manager preference hierarchies. Several potential preference scenarios are generated and results are compared using a full-scale test study, the Exeter Bascule Bridge. The framework successfully supports an informed design of measurement systems by providing an extensive set of alternatives, including the best solution defined probabilistically and for specific conditions when other near-optimal solutions might be preferred.
\end{abstract}

Keywords: System identification; Sensor placement; Multi-criteria decision making; SMAA-PROMETHEE; Error-domain model falsification.

\footnotetext{
${ }^{1}$ ETH Zurich, Future Cities Laboratory, Singapore-ETH Centre, 1 CREATE Way, CREATE Tower, 138602 Singapore.

2 EPFL, Applied Computing and Mechanics Laboratory, CH-1015 Lausanne, Switzerland; Email: numa.bertola@epfl.ch.

${ }^{3}$ ETH Zurich, Future Resilient System, Singapore-ETH Centre, 1 CREATE Way, CREATE Tower, 138602 Singapore. Current address: Land and Materials Management Division, National Risk Management Research Laboratory, U.S. Environmental Protection Agency (EPA) Office of Research and Development, 26 W. Martin Luther King Drive MS 483, Cincinnati, Ohio, 45268, USA.

${ }^{4}$ Department of Economics and Business, University of Catania, Corso Italia, 55, 95129 Catania, Italy.
} 
36 Much civil infrastructure was built between the end of the 1800s and 1970, and therefore, many elements have reached the end of their theoretical lifetime [1]. Due to the scarcity of economic and material resources, evaluating the replacement of infrastructure is a critical challenge, requiring good asset-management decision making. As infrastructure is designed and built using justifiably conservative behavior models (usually a finite element model), there are often significant levels of reserve capacity in the as-built state [2]. Knowledge of true structural behavior ensures more informed asset management for tasks such as maintenance, replacement and intervention design.

Continuous monitoring and periodic bridge load tests have been widely used in the previous decades to understand existing bridge behavior [3]. Since updated models need to be accurate, the interpretation of in-situ measurements is a critical task. However, the structural-parameter identification is a typical inverse problem where effects (measurements) are measured instead of causes (inputs of behavior models). The difficulties associated with such challenges have been recognized by many researchers, for example [4], [5].

Once field measurements are collected, a model-based structural-identification methodology is used to improve the knowledge of the true behavior of a structure. Many approaches for data interpretation are possible. For example, residual minimization [6] and Bayesian updating [7], [8] have been proposed. However, Pasquier et al. [9] observed that for a range of applications these model calibration methodologies, applied using traditional assumptions of independent zero-mean Gaussian error distribution forms, are often not applicable to civil infrastructure. Large systematic uncertainties present in behavior models often result in a biased identification of model parameters. Also, the magnitude of the bias modifies the correlation between measurements. To overcome such challenges, a multi-model approach has been proposed [10], [11], where outcomes are a set of candidate models that explain the measurements.

A probabilistic extension of the multi-model approach, called error-domain model falsification (EDMF) was presented [12]. In a first stage, the behavior model of the structure is built based on prior engineering knowledge. Once model parameters to be identified are selected, a population of model instances is generated, where a model instance is unique set of model parameter values. Thresholds bounds, representing the maximum explainable differences between model predictions and measurements, are computed probabilistically from nonparametric model uncertainties and measurement uncertainties. Eventually, candidate models that provide plausible explanations of field measurements are identified. This methodology has been successfully applied to tens of full-scale bridges in order to evaluate their reserve capacity, for example [13], [14]. Since outcomes of structural-identification methodologies depend on the choice of the sensor configuration, research into optimal-sensor-placement strategies is growing. The selection of good sensor locations has been proposed according to its information content, such as: maximizing the determinant of Fisher information matrix [15], [16], minimizing the information entropy in posterior model-parameter distribution [17], [18] and maximizing information entropy in multiple-model predictions [19], [20]. As the question of sensor placement usually involves large discrete sets of possible sensor locations, an optimization algorithm is required to find good solutions. Most authors have proposed reducing the computational effort using greedy optimization algorithms [21]. A hierarchical algorithm for sensor placement using the concept of joint entropy was introduced by [22] and was extended by [23] for structural identification to account for mutual information between sensor types and load tests. Although an optimal sensor configuration should involve multiple criteria, most studies have focused only on information-gain criteria. Additional features should also be taken into account in order to define good sensor configurations in practical situations. This 
includes information effectiveness, costs, installation constraints and robustness of information gain to hazards that may deactivate sensors.

Some studies have recognized tradeoffs between two sensor-placement criteria. The risk of over-instrumentation was investigated by comparing the cost of monitoring with information gain [24], [25]. A multi-criteria-decision-making approach to include several information-gain metrics and the cost of monitoring was presented by [26]. An adaptive sensor-placement methodology selecting first sensor locations according to their information content and giving freedom to engineers to place remaining sensors according to installation constraints was presented by [27]. Although [28] used the expected performance of a sensor configuration to detect outliers in sparse static measurements, this study did not provide insights for optimal sensor placement. A sensor configuration which is robust in terms of information gain to sensor failure for pipe-leaking detection using a model-free methodology was provided by [29]. While some studies have investigated two attributes for optimal sensor placement, no work has involved a more comprehensive investigation of multiple characteristics of a sensor configuration. In the presence of multiple conflicting criteria that create complex tradeoffs, finding good solutions involves reference to asset-manager preferences. The potential of that Multiple Criteria Decision Analysis (MCDA) methods in civil engineering was shown by [30], [31].There are no studies that have adapted MCDA to sensor placement for structural identification.

MCDA supports measurement-system design since it is an analysis that helps decision makers evaluate alternatives according to several and sometimes conflicting criteria [32]. Advantages of MCDA are that it aids transparent selection of important criteria, the inclusion of preferences of multiple stakeholders and the provision of a comprehensive evaluation of the alternatives in the form of a score, ranking or classification [33]. Several MCDA methods were developed over recent decades, including outranking strategies that are used by PROMETHEE [34], ELECTRE [35] and multi-attribute utility theory (MAUT) [36], [37]. Stochastic Multi-criteria Acceptability Analysis (SMAA) [38] accommodates possible ambiguities and uncertainties in model input and it provides a probabilistic evaluation (e.g., ranking, scoring, classification) of alternatives. Due to the increasing need for assessing robustness and credibility of decision recommendations, several approaches have been proposed to integrate SMAA with classical MCDA methods, including PROMETHEE [39], ELECTRE [40], Choquet integral [41] and stochastic ordinal regression [42].

This paper proposes a decision-support framework for measurement-system design. There are two principal objectives. First, a set of performance criteria for measurement system for structural identification is developed using a set of features that defines the optimal measurement system. Then, to provide an information-rich guidance in terms of recommended measurement system according to asset-manager preferences, a tiered strategy is proposed. The applicability of the framework is demonstrated using a full-scale test study and using several scenarios of possible asset-manager preferences.

The study is structured as follow. First, background methodologies including the structuralidentification framework and the information-gain assessment of measurement systems are presented in Section 2. Then, the methodology to support decision in terms of recommended measurement-system design for structural identification is shown in Section 3. Section 4 presents the full-scale case study and this is followed by results in terms of recommended number of sensors and number of load tests according to asset-manager preferences. Finally, results are discussed and compared with results from more traditional approaches for measurement-system design. Conclusions and recommendations for future research close the discussion. 


\section{Background}

132 In this section, background methodologies that are necessary to understand this study are presented. First, the structural-identification methodology is presented in Section 2.1. Then, the hierarchical algorithm, based on the joint-entropy objective function for sensor placement, is described in Section 2.2.

\subsection{Structural identification - Error-domain model falsification}

Initially proposed in probabilistic terms by [12], error-domain model falsification (EDMF) is an easy-to-use structural-identification methodology. The method uses information provided by field measurements to identify plausible models among an initial set of possible model instances.

First, an initial population of model instance $\Theta_{k}$ is generated by sampling indeterminate parameters of behavior models $\theta_{\mathrm{k}}=\left[\theta_{1}, \theta_{2}, \ldots, \theta_{\mathrm{n}}\right]^{\mathrm{T}}$ within range, which are defined using prior knowledge on the structure. Then, for each measurement location, $i \in\left\{1, \ldots, n_{y}\right\}$, modelinstance predictions of the structural response are compared with field measurements. Since model-prediction uncertainties $U_{i, g}$ and measurement uncertainties $U_{i, \hat{y}}$ are unavoidable, the model prediction $g_{k}\left(i, \Theta_{k}\right)$ and the field measurement $\hat{y}_{i}$ at a sensor location $i$, are linked to the true behavior $R_{i}$ using the following equation:

$$
g_{k}\left(i, \Theta_{k}\right)+U_{i, g_{k}}=R_{i}=\hat{y}_{i}+U_{i, \hat{y}} \forall i \in\left\{1, \ldots, n_{y}\right\} .
$$

Following [11], modeling and measurement uncertainties $\left(U_{i, g}\right.$ and $\left.U_{i, y}\right)$ are combined in a unique distribution $U_{i, c}$ and Equation (1) can be rewritten in Equation (2). The difference between the model prediction and the field measurement at a sensor location $i$ is called the residual $r_{i}$.

$$
g_{k}\left(i, \Theta_{k}\right)-\hat{y}_{i}=U_{i, c}=r_{i} .
$$

EDMF selects plausible behavior model instances by falsifying those for which residuals exceed threshold bounds, according to a confidence level fixed at $95 \%$ of the combined uncertainty. Model instances for which residuals do not exceed threshold bounds at each sensor location are included in the candidate model set (CMS). As the available information is usually not sufficiently accurate to justify any further discrimination, model instances belonging to the CMS are considered to be equivalently likely [43].

If all initial model instances are falsified, the entire model class is falsified. The model class is a parameterized behavior model, where model-parameter values need to be assign in model instances. This means that no model instance is compatible with observations given the current estimation of model and measurement uncertainties. This is a sign of possible incorrect assumptions in the model-class definition and uncertainty estimation. Complete falsification leading to subsequent re-evaluation of assumptions one of the main advantages of EDMF compared with other structural-identification methodologies, such as residual minimization or Bayesian updating [44].

\subsection{Sensor-placement algorithm - Hierarchical algorithm}

Prior to measuring a structure, a sensor-placement strategy has the potential to identify optimal sensor locations when a limited knowledge of model-parameter values is available. Once the numerical model is built and the model class is selected, prediction data from a population of model instances is a typical start to evaluate information gained by sensor locations. 
The information entropy, from information theory, was introduced as a sensor-placement objective function for system identification [18]. At each sensor location $i$, the range of prediction is divided in intervals based on the combined uncertainty $U_{i, c}$ (Equation (2)). The probability that model instance $\mathrm{m}_{\mathrm{i}, \mathrm{j}}$ falls inside the $\mathrm{j}^{\text {th }}$ interval in $N_{I, i}$ intervals is equal to: $P\left(y_{i, j}\right)=m_{i, j} / \sum m_{i, j}$. The information entropy $H\left(y_{i}\right)$ is evaluated for a location $i$ as:

$$
H\left(y_{i}\right)=-\sum_{j=1}^{N_{I, i}} P\left(y_{i, j}\right) \log _{2} P\left(y_{i, j}\right) .
$$

To consider the redundancy of information gain between sensor locations, a new sensorplacement objective function called joint entropy was introduced by [22]. The joint entropy assesses the information entropy between sets of predictions taking into account the mutual information between them. For a set of two sensors, it is defined as:

$$
H\left(y_{i, i+1}\right)=-\sum_{k=1}^{N_{I, i+1}} \sum_{j=1}^{N_{I, i}} P\left(y_{i, j}, y_{i+1, k}\right) \log _{2} P\left(y_{i, j}, y_{i+1, k}\right)
$$

where $k \in\left\{1, \ldots, N_{I, i+1}\right\}$ and $N_{I, i+1}$ is the maximum number of prediction intervals at the $\mathrm{i}+1$ location and $i+1 \in\left\{1, \ldots, n_{s}\right\}$ with the number of potential sensor locations $n_{\mathrm{s}}$. The joint entropy is less than or equal to the sum of the individual information entropies of the sets of predictions. Equation (5) presents the joint entropy of two sensors, where $I$ is the mutual information between sensors $i$ and $i+1$.

$$
H\left(y_{i, i+1}\right)=H\left(y_{i}\right)+H\left(y_{i+1}\right)-I\left(y_{i, i+1}\right)
$$

The hierarchical algorithm [22] is a sequential algorithm (greedy search) and organizes model instances in a tree structure. At each step of the calculation, the hierarchical algorithm selects the location with the largest joint-entropy value. It was shown to outperform traditional sequential algorithms with forward or backward strategies. In addition, the quality of structural identification is also affected by the excitation (i.e. static load test). A modification of the hierarchical algorithm was proposed in [23] to consider mutual information between load tests based on joint entropy. Equation (6) describes the joint-entropy evaluation for a sensor location i with two load tests, where $j \in\left\{1, \ldots, \mathrm{N}_{\mathrm{I}, \mathrm{i}_{1}}\right\}$ and $N_{I, i_{l}}$ is the maximum number of intervals at the location $i$ associated with a load test $1, k \in\left\{1, \ldots, \mathrm{N}_{\mathrm{I}, \mathrm{i}_{1+1}}\right\}$ and $N_{I, i_{l+1}}$ is the maximum number of intervals at the location $i$ associated with another load test $l+1 \in\left\{1, \ldots, \mathrm{n}_{\mathrm{LT}}\right\}$ with the number of potential load tests $n_{L T}$. The hierarchical algorithm is able to evaluate information gained by a measurement system, composed of a sensor configuration and a set of load tests.

$$
H\left(y_{i_{l}, i_{l+1}}\right)=-\sum_{k=1}^{N_{I, i} i_{l+1}} \sum_{j=1}^{N_{I}, i_{l}} P\left(y_{i_{l}, j}, y_{i_{l+1}, k}\right) \log _{2} P\left(y_{i_{l}, j}, y_{i_{l+1}, k}\right)
$$

\section{Framework for multi-criteria analysis for measurement-system recommendation}

In order to assess accurately the reserve capacity of a structure, the estimation of various unknown physical and geometrical properties and boundary conditions is required. The aim of field measurements is to enhance knowledge of uncertain model parameters and then improve accuracy of behavior-model predictions. Choices in terms of sensor types, sensor locations and load tests, constituting altogether a measurement system, are critical to do an effective structural-identification assessment.

The design of the appropriate measurement system is challenging due to its multi-criteria nature and large amount of possible sensor configurations. Although the second problem was acknowledged in the literature and often solved using a sequential search [21], most studies focus only on the information-gain criterion of the measurement system. In the present study, a framework is proposed to consider a multi-criteria approach for measurement-system design without compromising the effective computation developed in previous studies. The framework for measurement-system design is built upon three phases (Figure 1). First, the 
relevant possible measurement-system options are identified and the set of criteria to evaluate their performance is chosen (Phase 1). Then, an iterative procedure to select the relevant MCDA method is conducted (Phase 2). Eventually, a stepwise process to recommend a measurement system is presented (Phase 3). Each phase will be described in detail in Sections

\section{$222 \quad 3.1$ to 3.3 .}
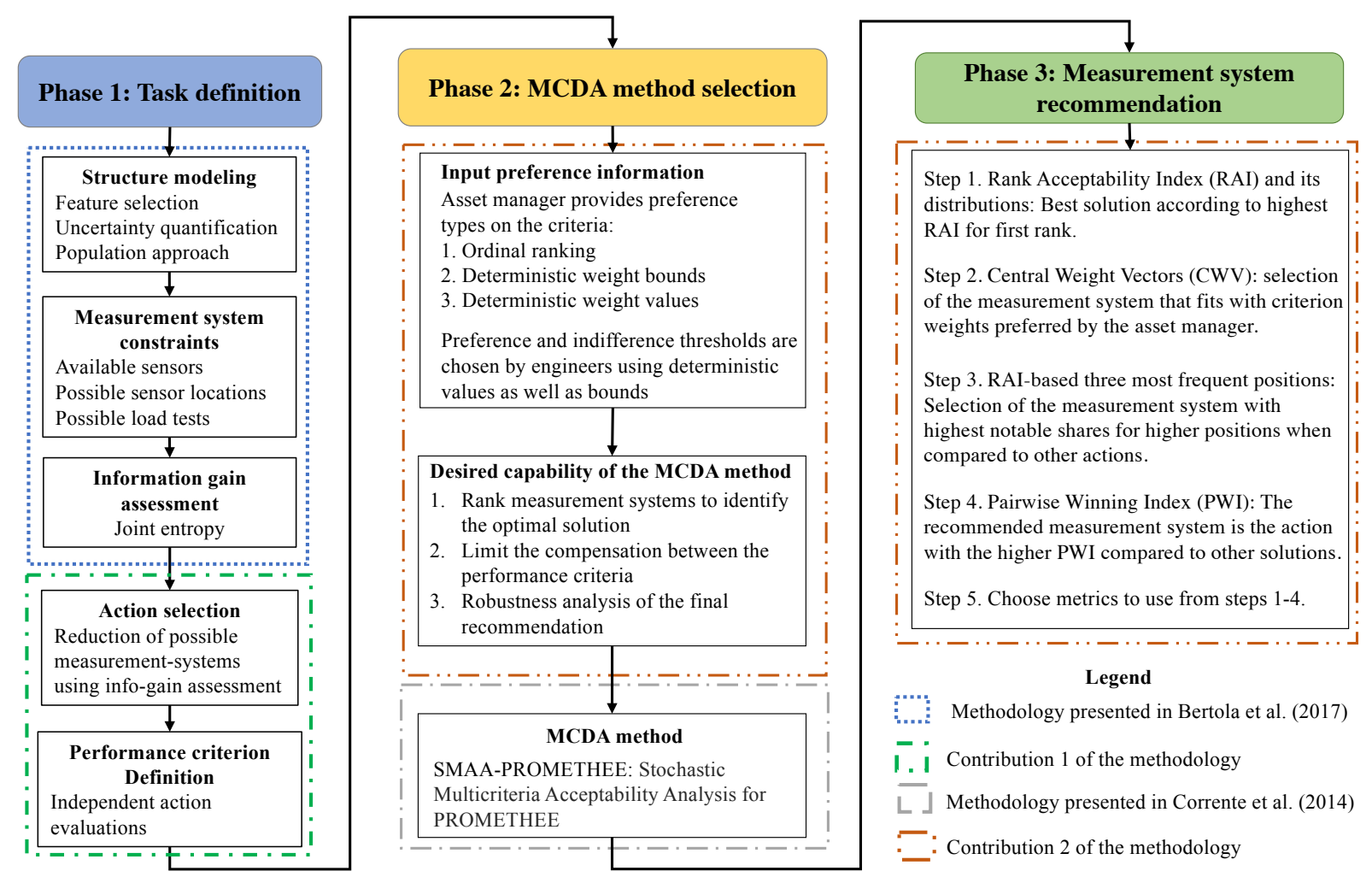

Figure 1: Structure of the framework for multi-criteria measurement system design. Phase 1: task definition; Phase 2: MCDA method selection; Phase 3: measurement-system recommendation.

\subsection{Phase 1: Task definition}

This section presents the first phase of the framework, which involves defining the set of options for the MCDA. This phase is divided into three parts. First, monitoring constraints in terms of available sensor types, possible sensor locations and load tests are defined in order to generate inputs of possible measurement systems. Then, the information-gain is assessed with respect to number of sensors to reduce the number of possible options to consider in the MCDA. Eventually, other performance criteria for the MCDA are defined and each remaining option is evaluated for each criterion independently.

\subsubsection{Initial prediction sets for measurement-system design}

In order to perform a model-based measurement-system-design strategy, several steps are required to generate initial sets of predictions. First, a numerical behavior model, such as a finite element model of a bridge, is built to obtain quantitative predictions of measurable variables. As any numerical model requires geometrical and mathematical simplifications, a significant amount of non-parametric uncertainty is involved. Non-parametric uncertainties, influencing the evaluation of measurement data, must be estimated quantitatively. Model 
parameters, which have the highest impact on model predictions, are selected through sensitivity analyses. Then, available sensors and their respective possible locations are identified along with possible load tests.

Once these assumptions are chosen, multiple model instances are generated using a sampling technique to obtain a discrete population of model-parameter values within plausible ranges. For each set of load tests, model-instance predictions at each possible sensor locations are computed, constituting the prediction sets used in the information-gain assessment (Section 3.1.2).

\subsubsection{Information-gain assessment and option selection}

Once prediction sets are generated (Section 3.1.1), evaluations of measurement systems in terms of performance criteria can be completed. However, the number of measurement-system combinations has a computational complexity $\mathrm{O}\left(2^{\mathrm{n}}\right)$, where $\mathrm{n}$ is the number of possible sensor locations [22]. Additionally, if several performance metrics are evaluated for each measurement system, the computational time for each iteration may increase significantly compared to a single objective-function evaluation. Therefore, it was chosen to reduce the set of measurement-system options using a single objective function based on information-gain assessment. For each set of load tests, the hierarchical algorithm described in Section 2.2 is used to find a near-optimal sensor configurations with respect to number of sensors. The aim is to reduce the set of possible measurement systems to options providing a significant amount of information. As the sensor-placement algorithm uses a greedy approach for sensor placement, the complexity is $\mathrm{O}\left(\mathrm{n}^{2}\right)$ with respect to the number of possible sensor locations, reducing considerably the computational time of MCDA [22]. If multiple sets of load tests exist, the hierarchical algorithm must be performed for each set independently. For each set of load tests, joint-entropy values as function of the number of sensor are shown as in Figure 2, where results of four sets of load tests are presented. Each mark corresponds to a specific measurement system that could be evaluated in the MCDA (Phase 3, Figure 1).

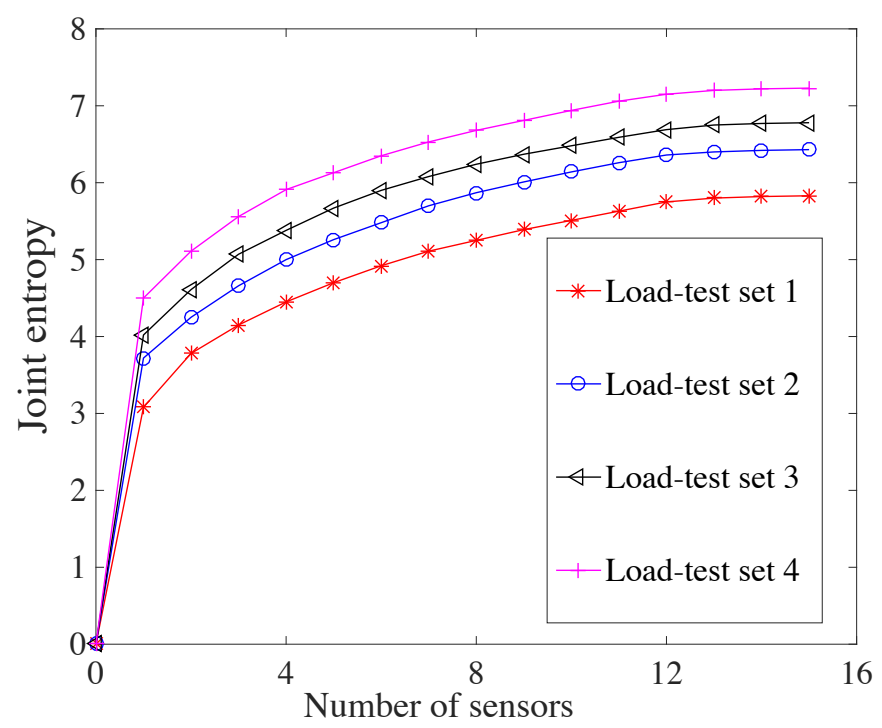

\subsubsection{Definition of measurement-system criteria}

Figure 2 Information-gain assessment as function of number of sensors for load-test configurations using the hierarchical algorithm (Section 2.2).

A measurement system is recommended to asset managers as the best solution if it has multiple characteristics. First, the measurement system must be informative, meaning that a significant 
gain of information is expected. Secondly, the measurement system should be cost effective to avoid expenses that are not justified by the information gained. Then, the sensor installation should be taken into account as it may disturb the traffic, generate additional costs and increase the risk of sensor failure. Eventually, assessing a full-scale structure in its environment requires consideration of the possibility of sensor failures. Typically, $20 \%$ of sensors are expected to fail and to not provide useful measurements [45]. The robustness to test hazards of the measurement system has not been treated in the literature on measurement-system design. In the present study, two new performance criteria to include the robustness to test hazards are introduced: the ability of the measurement system to identify outlier measurements and the loss of information gain in case of failure of the best sensor. Therefore, five performance criteria will be used and their characteristics are presented in Table 1. Measurement-system-design criteria are presented in sub-sections below.

Table 1 Characteristics of the measurement system with respect to performance criterion.

\begin{tabular}{c|ccc}
\hline \multirow{2}{*}{$\begin{array}{c}\text { Performance } \\
\text { criterion }\end{array}$} & \multicolumn{3}{|c}{ Characteristic of the measurement system } \\
\cline { 2 - 4 } & Informative $\begin{array}{c}\text { Practical } \\
\text { installation }\end{array}$ & $\begin{array}{c}\text { Robust to } \\
\text { test hazards }\end{array}$ & $\begin{array}{c}\text { Cost } \\
\text { effective }\end{array}$ \\
\hline $\begin{array}{c}\text { Information gain } \\
\text { Costs of monitoring }\end{array}$ & $\checkmark$ & & $\checkmark$ \\
$\begin{array}{c}\text { Ability to detect outliers } \\
\text { Loss of information in } \\
\text { case of sensor failure } \\
\text { Installation constraints }\end{array}$ & & $\checkmark$ & \\
\hline
\end{tabular}

\subsubsection{Information gain}

In order to evaluate the informative characteristic of a measurement system, the information gain is assessed using the hierarchical algorithm (Section 2.2). The joint-entropy metric evaluates the ability of a measurement system to discriminate between candidate and falsified model instances. The joint-entropy value is bounded between $\left[0 ; \log _{2}(N)\right]$, where $N$ is the number of model instances involved. Typically, predictions of 1,000 model instances are generated using a FEM model and thus the joint entropy value is bounded between 0 and 10 . A low joint-entropy value means that model instances could not be easily discriminated using the measurement system and the information gain is poor. Therefore, the joint-entropy metric must be maximized in order to have an informative measurement system.

\subsubsection{Costs of monitoring}

299 In this performance criterion, the cost of the monitoring system is assessed. The total cost of 300 monitoring is composed of all costs related to the bridge load testing such as instruments and 301 truck rentals. In order to have a cost-effective measurement system, the cost of monitoring 302 must be minimized.

\section{3.1.3.3 Ability to detect outliers}

304 In order to assess the robustness of a sensor configuration to test hazards, two new metrics are 305 proposed: the ability to detect the presence of an outlier in measurements and the loss of 306 information in case of sensor failure (Section 3.1.3.4). A methodology to detect the presence 307 of outliers in EDMF framework was proposed by [28]. The methodology compares excepted 308 information gain of measurement systems iteratively including and excluding a particular sensor in the sensor network with the true difference of candidate models if this particular sensor is involved or not in the falsification once the bridge is monitored. The aim is to provide 
311 a reasonable degree of confidence to evaluate a sensor as an outlier when only sparse static measurements exist. However, as the original methodology requires field measurements, it must be adapted to be used as a performance criterion for measurement-system design.

For a given set of load tests, the cumulative density functions (CDFs) of expected number of candidate models are computed and compared for the entire sensor network and for the sensor

\section{5} network without the particular sensor $\mathrm{k}$ (Figure 3a). The difference between CDFs is presented in Figure 3b. At the measurement-system-design stage, true \#CMs are unknown and thus the true value of $\Delta_{k}$ is unknown. In the case of a faulty sensor, a small value of $\Delta_{k}$ means that the detection of this sensor as an outlier is more likely. Therefore, in order to be conservative, it is assumed that $\Delta_{k}$ is equal to the maximum difference in CDFs.

The procedure is then repeated for each sensor in the measurement system. Since the impact of an undetected faulty sensor on the structural-identification process (Section 2.1) is not related to the expected performance of this sensor, all sensors present the same risk for wrong system identification. The average value of $\Delta_{k}$ for a measurement system is thus taken to be a metric to measure the average ability of a measurement system to detect an outlier measurement (Equation (7)). A small value of $\Lambda$ means that the measurement system is more likely to detect a presence of an outlier in field measurements. Therefore, $1-\Lambda$ must be maximized to provide a measurement system which is able to detect the presence of outlier(s) in measurements once the structure is monitored.

$$
\Lambda=\frac{1}{N} \sum_{k=1}^{N} \Delta_{k}
$$

A) CDFs of sensor networks

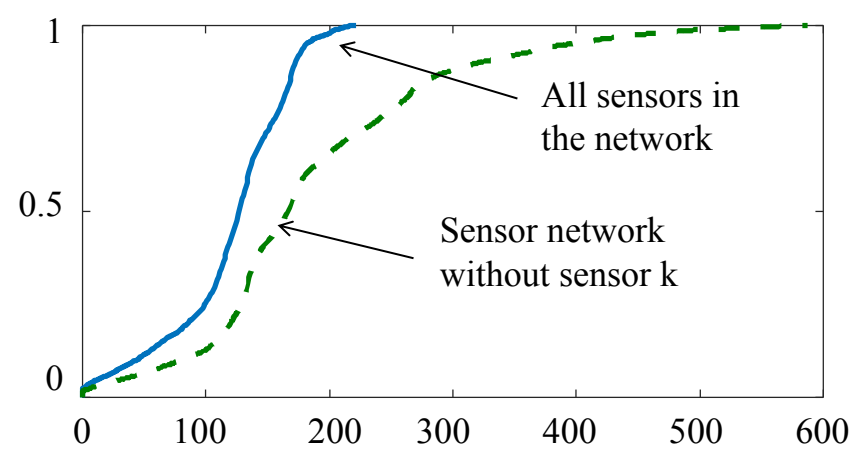

B) Difference between CDFs

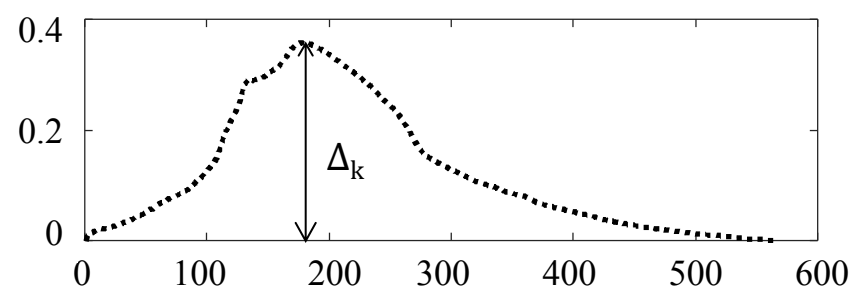

Number of candidate models

Figure 3 Outlier-detection methodology at the measurement-system-design stage. A) cumulative distribution functions of the number of candidate models using all sensors and the network without a sensor k. B) difference between cumulative distribution functions (CDFs) and measure of $\Delta_{k}$ for sensor $k$.

\subsubsection{Loss of information in case of sensor failure}

The second metric to assess the robustness of the information gain of a measurement system to test hazards is the loss of information in case of a sensor failure. The failure of the best 
sensor, defined as the first sensor selected by the hierarchical algorithm (Section 2.2), is assumed and the consequent loss of information is assessed. This approach is similar to the method proposed by [29] in the field of leak identification in water-pipe networks. First, the joint-entropy value $H_{S N}$ of the measurement system and the joint entropy without the best sensor in the measurement system $H_{S N-b e s t}$ are calculated. The difference of joint-entropy values between the two measurement systems $\Delta H$ represents the expected absolute loss of information. Then, $\Delta H$ is normalized with $H_{S N}$ to assess the robustness in terms of information of a measurement system. The metric (Equation (8)) must be minimized in order to provide a measurement system which is robust in terms of information loss due to the failure of the best sensor.

\subsubsection{Installation constraints}

$$
\Gamma=\frac{\Delta H}{H_{S N}}=\frac{H_{S N}-H_{S N-b e s t}}{H_{S N}}
$$

To evaluate the practical-installation characteristic of a measurement system, an installation constraints metric is added to the MCDA. The metric is case dependent and could for instance include additional costs for sensor locations, sensor types or installation time. In the present study, an additional cost is applied to some sensor locations as they require additional equipment to be reached (Section 4.3). Thus, additional installation costs are defined as an initial equipment cost plus a cost per sensor in a specific area. The installation cost must be minimized in order to have a sensor configuration which is practical to install.

\subsubsection{Independent option evaluation}

Once each performance criterion for sensor placement is defined, the set of options to consider in the MCDA (Section 3.1.2) can be evaluated for each criterion independently, creating a performance matrix with the measurement systems and criterion evaluations. This consists of the last step of the first phase of the framework (Figure 1). The second phase presents the selection of the adapted MCDA method for measurement-system design according to assetmanager preferences.

\subsection{Phase 2: MCDA-method selection}

Due to the conflicting nature of measurement-system performance criteria, such as information gain and cost of monitoring, it is usually not possible to identify the optimal measurement system by looking at each criterion separately in the performance matrix (Section 3.1.4). Recommending a measurement system to asset managers implies trade-offs between conflicting criteria, which is a problem typology particularly suitable for MCDA [33], [46]. In addition, ranking possible measurement systems by accounting for their overall performance is relevant to recommend suitable options to the asset manager (decision maker) [25]. Therefore, the use of an MCDA method is justified for the study of measurement-system design. The aim of this phase is to select the appropriate MCDA method according to the possible preference information of asset managers as well as the desired capabilities of the method (Phase 2, Figure 1).

For any MCDA method, recommendation in terms of measurement system is unsurprisingly influenced by asset-manager criterion-weighting preferences. Three types of asset-manager weighing preferences are realistic, namely ordinal rankings of criteria, deterministic weight bounds and deterministic weight values for each criterion. In addition, several distributions in terms of weights are possible, such as attributing more weights to information-gain criteria or a preference for monitoring system with a relatively low cost. A required characteristic of the selected MCDA method will be the ability to provide measurement-system recommendations for any asset-manager preference settings. 
385 A wide variety of settings of asset-manager preferences are modelled to evaluate the influence on the measurement-system recommendation. Three scenarios of possible orientation in terms of weighting preferences are defined in Table 2. First, a scenario where the asset-manager assigns an equal weight to each measurement-system criterion is proposed. Then, scenarios 2 and 3 imply a polarization of the criterion-weighting preference in the direction of the maximization of the information gain or a low-cost monitoring for scenarios 2 and 3 respectively.

392 Table 2 Possible preference scenarios of an asset manager.

393

394

395

396

397

398

399

400

401

402

403

404

\begin{tabular}{cl}
\hline Scenario & $\begin{array}{c}\text { Orientation of asset-manager } \\
\text { weighing preferences }\end{array}$ \\
\hline 1 & Equal weights \\
2 & Maximization of information gain \\
3 & Low-cost monitoring \\
\hline
\end{tabular}

Then, within the preference scenario, asset managers decide the nature of their preferences between performance criteria. Two types of possibilities have been developed to study the influence of such preferences on measurement-system evaluations: an ordinal choice with a ranking of criteria by order of preference, and a cardinal choice with bounds or deterministic values for criteria weights. According to the scenario of asset-manager preferences, Table 3 presents the order of importance of performance criteria, while Table 4 presents weight bounds for each performance criterion. Therefore, five settings of asset-manager weighting preferences, including a preference scenario associated with a preference type are created to understand the influence on the measurement-system recommendation for structural identification (Table 5). Settings are ordered according to the preference scenarios.

Table 3 Ordinal importance order for performance criteria.

\begin{tabular}{cccccc}
\hline \multirow{2}{*}{ Scenario } & \multicolumn{5}{c}{ Importance order of performance criteria } \\
\cline { 2 - 6 } & $\begin{array}{c}\text { Information } \\
\text { gain }\end{array}$ & $\begin{array}{c}\text { Cost of } \\
\text { monitoring }\end{array}$ & $\begin{array}{c}\text { Outlier } \\
\text { detection }\end{array}$ & $\begin{array}{c}\text { Loss of } \\
\text { information }\end{array}$ & $\begin{array}{c}\text { Sensor } \\
\text { installation }\end{array}$ \\
\hline $\begin{array}{c}\text { Maximization of } \\
\text { information gain } \\
\text { Low-cost } \\
\text { monitoring }\end{array}$ & 1 & 4 & 3 & 2 & 5 \\
\hline
\end{tabular}


Table 4 Weight bounds for a cardinal importance order for performance criteria.

\begin{tabular}{cccccc}
\hline \multirow{2}{*}{ Scenario } & \multicolumn{4}{c}{ Weight bounds or deterministic values of performance criteria } \\
\cline { 2 - 6 } & $\begin{array}{c}\text { Information } \\
\text { gain }\end{array}$ & $\begin{array}{c}\text { Cost of } \\
\text { monitoring }\end{array}$ & $\begin{array}{c}\text { Outlier } \\
\text { detection }\end{array}$ & $\begin{array}{c}\text { Loss of } \\
\text { information }\end{array}$ & $\begin{array}{c}\text { Sensor } \\
\text { installation }\end{array}$ \\
\hline $\begin{array}{c}\text { Equal weights } \\
\text { Maximization of }\end{array}$ & 0.20 & 0.20 & 0.20 & 0.20 & 0.20 \\
information gain \\
$\begin{array}{c}\text { Low-cost } \\
\text { monitoring }\end{array}$ & {$[0.35-0.50]$} & {$[0.10-0.15]$} & {$[0.15-0.20]$} & {$[0.15-0.20]$} & {$[0.10-0.15]$} \\
\hline
\end{tabular}

407

Table 5 Settings of asset-manager preferences.

\begin{tabular}{ccc}
\hline Setting & Preference scenario & Preference type \\
\hline 1 & Equal weights & Cardinal \\
2 & Maximization of information gain & Cardinal \\
3 & Maximization of information gain & Ordinal \\
4 & Low-cost monitoring & Cardinal \\
5 & Low-cost monitoring & Ordinal \\
\hline
\end{tabular}

409

410

411

412

413

414

415

416

417

418

419

420

421

422

423

424

425

426

427

In addition to weighting performance criteria differently, the engineering practice involves conducting comparisons between options by accounting for thresholds of performance [47]. When two options have similar metric values they can be considered as equal. When the difference of performances reaches a certain value (i.e. threshold), then an option is strictly preferred over the other. In MCDA terms, this situation can be modelled by indifference and preference thresholds. In the present study, thresholds are set using bounds (Table 6). The indifference threshold represents the greatest difference between evaluations of two options on criterion $g_{j}$ compatible with the indifference between them on this criterion. The preference threshold represents the lowest difference between evaluations of two options on criterion $g_{j}$, meaning that one is preferred over the other on this criterion [48]. This enables explicit representation of variations in preferences of asset managers. Criterion-bound values were chosen based on engineering judgement, discussions with asset managers and heuristics. Concerning information gain, outlier detection and robustness to sensor failure criteria, lowest values of preference thresholds were estimated based on the repeatability of Monte-Carlo simulations of the hierarchical algorithm (Section 2.2) and outlier-detection methodology (Section 3.1.3.3).

Table 6 Indifference $q$ and preference $\mathrm{p}$ threshold bounds for performance criteria.

\begin{tabular}{cc|cc|cc|ccc|cc}
\hline \multicolumn{4}{c}{ Indifference and preference thresholds for performance criteria } \\
\hline \multicolumn{2}{c}{$\begin{array}{c}\text { Information } \\
\text { gain }\end{array}$} & \multicolumn{2}{c}{$\begin{array}{c}\text { Cost } \\
\text { of monitoring }\end{array}$} & \multicolumn{2}{c}{$\begin{array}{c}\text { Outlier } \\
\text { detection }\end{array}$} & \multicolumn{2}{c}{$\begin{array}{c}\text { Robustness } \\
\text { to sensor failure }\end{array}$} & \multicolumn{2}{c}{$\begin{array}{c}\text { Sensor } \\
\text { installation }\end{array}$} \\
\hline $\mathrm{q}$ & $\mathrm{p}$ & $\mathrm{q}$ & $\mathrm{p}$ & $\mathrm{q}$ & $\mathrm{p}$ & $\mathrm{q}$ & $\mathrm{p}$ & $\mathrm{q}$ & $\mathrm{p}$ \\
\hline$[0.05-$ & \multirow{2}{*}[3-4]{} & {$[500-$} & {$[4500-$} & {$[0.01-$} & {$[0.35-$} & {$[0.02-$} & {$[0.12-$} & {$[500-$} & {$[4500-$} \\
$0.2]$ & & $1000]$ & $5500]$ & $0.03]$ & $0.40]$ & $0.05]$ & $0.15]$ & $1000]$ & $5500]$ \\
\hline
\end{tabular}


Regarding the desired capability of the MCDA method, the principal requirement is to rank measurement-system options. Another goal involves limiting the compensation between performance criteria, meaning that the good performance of a measurement-system on one (or more) criterion cannot compensate for the poor performance on one (or more) criterion. This condition is important to avoid high rankings of poorly performing measurement systems. Furthermore, a single deterministic ranking is not desired, as it does not provide indication of the stability (hence credibility) of the measurement-system recommendation. An additional requirement is thus the assessment of the robustness in terms of ranking of measurementsystem recommendations. The strategy incorporates the concept of robustness analysis [49], meaning that multiple versions of the decision-support methodology is intended to derive probabilistically-characterized results, which in this case are measurement-system rankings. These requirements were used to screen the relevant literature [49]-[53] to search for the most appropriate method. Eventually, the SMAA-PROMETHEE method satisfied all requirements and it was thus chosen for the MCDA to support measurement-system design decision making for bridge load testing according to asset-manager preference settings. The methodology is presented in detail below.

\subsubsection{SMAA-PROMETHEE methodology}

The SMAA-PROMETHEE method is based on two very families of MCDA methods, 446 PROMETHEE and Stochastic Multi Criteria Acceptability Analysis (SMAA). In this Section, 447 the SMAA-PROMETHEE methodology is briefly introduced. PROMETHEE, which stands 448 for Preference Ranking Organization Method for Enrichment Evaluations, was introduced by [54] and it is an outranking methodology based on pairwise comparisons. It has been extensively used to solve MCDA problems [55], [56].

A single ranking in PROMETHEE can be obtained following the procedure presented below. First, preference parameters for the MCDA need to be defined. A weight $w_{j}$ for each criterion $g_{j}$ is set such that $w_{j} \geq 0$ for all $j=1, \ldots, n$, and $\sum_{j=1}^{n} w_{j}=1$. Each weight, $w_{j}$, is representative of the importance of the criterion $g_{j}$ inside the whole family of criteria $G(|G|=$ $n$ ). Then, an indifference $q_{j}$ threshold and a preference $p_{j}$ threshold for each criterion $g_{j}$ are defined such that $q_{j}<p_{j}$. A partial preference function $P_{j}(a, b)$ is defined for each criterion $g_{j}$, representing the degree of preference of option $a$ over option $b$ on criterion $g_{j}$. The higher the preference function $P_{j}(a, b)$, the more option $a$ is preferred to option $b$ on criterion $g_{j}$. Six preference functions have been defined [34]. For instance, in the case of the V-shape function, the preference function is defined following Equation (9).

$$
P_{j}(a, b)=\left\{\begin{array}{ccc}
1 & \text { if } & g_{j}(a)-g_{j}(b) \geq p_{j}, \\
\frac{\left[g_{j}(a)-g_{j}(b)\right]-q_{j}}{p_{j}-q_{j}} & \text { if } & q_{j}<g_{j}(a)-g_{j}(b)<p_{j}, \\
0 & \text { if } & g_{j}(a)-g_{j}(b) \leq q_{j} .
\end{array}\right.
$$

Then, the comprehensive preference function $\pi(a, b)$ (Equation (10)) for each ordered pair of options $(a, b) \in A \times A$ is calculated. This represents the degree of preference of option $a$ over option $b$ taking into account all criteria simultaneously, where $A$ denotes the set of options.

$$
\pi(a, b)=\sum_{j=1}^{n} w_{j} \cdot P_{j}(a, b) .
$$

Consequently, for each option $a \in A$, the positive $\Phi^{+}(a)$, negative $\Phi^{-}(a)$ and net $\Phi(a)$ flows can be calculated (Equations (11) to (13)). The positive flow $\Phi^{+}(a)$ quantifies how much option $a$ is preferred, on average, to the other options (Equation (11)), while the negative flow $\Phi^{-}(a)$ quantifies how much, on average, other options are preferred to option a (Equation (12)). The net flow $\Phi(a)$ (Equation (13)) is the balance between positive and negative flows. This expresses the strength of option $a$ with respect to the set of options. The application of the 
PROMETHEE method thus allows to rank options to be ranked, according to their value of net flow $\Phi(a)$ from the best to the worst.

Based on calculations of the above flows, several PROMETHEE methods can be defined [34]. In this study, PROMETHEE II was selected. In this method, given options a and $b$, a is preferred to b if and only if $\Phi(a)>\Phi(b)$, while, a and b are indifferent iff $\Phi(a)=\Phi(b)$. Therefore, options in the set A can be ordered from the best to the worst on the basis of their net flows.

The computation of the net flow is based on the definition of weight $w_{j}$, indifference threshold $q_{j}$ and preference threshold $p_{j}$ for each criterion $g_{j}$. The choice of values for MCDA parameters could be too demanding or too restrictive for the decision maker (DM). Instead of singular values for each weight, the DM can be more confident in providing preference information such as a comparison between importance of criteria (criterion $g_{i}$ is more important than criterion $g_{j}$ or criteria $g_{i}$ and $g_{j}$ are equally important), rank criteria by order of importance $\left(g_{(1)}>g_{(2)}>\cdots>g_{(n)}\right.$, where $>$ stands for "is more important than") or giving deterministic bounds for weights $\left(w_{j} \in\left[w_{j}^{-}, w_{j}^{+}\right]\right.$, where $w_{j}^{-}$and $w_{j}^{+}$stand for upper and lower bounds of the weight attributed to criterion $g_{j}$ ). In a similar way, with respect to the indifference and preference thresholds, the DM can provide intervals of variation such as $q_{j} \in$ $\left[q_{j *}, q_{j}^{*}\right]$ or $p_{j} \in\left[p_{j *}, p_{j}^{*}\right]$.

The advantage of giving such preference information on MCDA parameters is counterbalanced from the variety of binary relations that can be obtained. To take into account the variety of built relations, the SMAA methodology [38] is a relevant approach. SMAA considers the plurality of MCDA parameters compatible with the DM preference information by giving recommendations in statistical terms. Introduced in [39], SMAA-PROMETHEE generates typically 100,000 samples, within a set of MCDA parameters (such as including weights $w_{j}$, indifference $q_{j}$ and preference $p_{j}$ thresholds) that are compatible with the preference information provided by the DM. Then, the PROMETHEE method is applied to build indifference and preference relations for each of these samples. Options are then ranked probabilistically.

\subsection{Phase 3: Measurement-system recommendation}

Once the set of options is evaluated independently for each criterion (Phase 1, Figure 1) and the MCDA method is selected (Phase 2, Figure 1), SMAA-PROMETHEE is used to provide a recommendation in terms of measurement system to the asset manager. The selected MCDA method provides several outputs [55], that have been tailored for this study to provide a stepwise identification of the measurement system (Phase 3, Figure 1). To offer a rich guidance to asset managers in terms of recommended measurement systems, four metrics are used:

- Rank acceptability index (RAI) $b^{r}(a)$ : it gives the frequency with which option $a$ takes the $r$-th place in the complete ranking. In this study, the focus is on the best first place, $\max _{a \in A} b^{1}(a)$, which is the highest frequency of an option being first.

- Central weights vector $(\mathrm{CWV}) w^{c}(a)$ : it is the barycenter of the weights giving to option $a$ the first position. It expresses the average preferences making option $a$ the recommended measurement system. 
- Most frequent position (MFPi) $b^{M F P i}(a)$ : Three most frequent positions of option $a$ are given with their respective frequency [57], [58].

- Pairwise winning index (PWI) Pref $(a, b)$ : it gives the frequency with which option $a$ is preferred to option $b$.

The procedure to provide a measurement-system recommendation is built upon four steps. Asset managers can decide to stop once they are satisfied with the outcome. In the first step, the procedure starts with looking globally at the RAI and its distributions.

If the option with the highest RAI for the first rank $\max _{a \in A} b^{1}(a)$ is over a certain threshold (i.e. 70\%), SMAA-PROMETHEE gives a clear preference to define this option as the best solution. This option can therefore be recommended to the asset manager.

When there is no clear preference for an option (i.e. $\max _{a \in A} b^{1}(a)<70 \%$ ) or more insights are required by the asset manager, the second step involves at the central weight vector. With this metric, each option with a $b^{1}(a) \geq 10 \%$ is shown and its barycenter of weights is presented, allowing asset managers to choose measurement system according to their refined criterionweighting preferences.

If asset managers do not wish to indicate any preferred weighing profile related to any solution, the recommendation can be derived in step 3 by looking at the three most frequent positions. If an option has notable higher frequencies for the first positions compared to other options, this measurement system is statistically defined as a better solution.

If ambiguity between two options $(a, b)$ still occurs, the last step involves evaluation of the pairwise comparison index, which allows a direct comparison of competing options. This index indicates the frequency with which option $a$ is preferred over option $b$. The measurement system with the largest value will be recommended to the asset manager.

\section{Case study}

\subsection{The Exeter Bascule Bridge}

The Exeter Bascule Bridge (UK) is designed to be lifted to allow the transit of boats along a canal connected to the river Exe. The light-weight deck, consisting of a series of flanked aluminum omega-shaped profiles, is connected to 18 secondary beams which are bolted to two longitudinal girders. Built in 1972, the bridge has a single span of $17.3 \mathrm{~m}$ and a total width of about $8.2 \mathrm{~m}$, carrying the traffic and a footway. In the static system, North-bank supports are hinges, while the South-bank is simply supported. Two hydraulic jacks, activated during lifting operations, are connected to the two longitudinal girders on the North-bank side. Figure 4 shows the elevation and a photograph of the bridge during a static load test. Until 11 strain gauges and 1 deflection measurement, using a target on the bridge and a precision camera on the side of the bridge, are available sensors for monitoring. The recommended measurement system can therefore include a maximum of 12 sensors. 

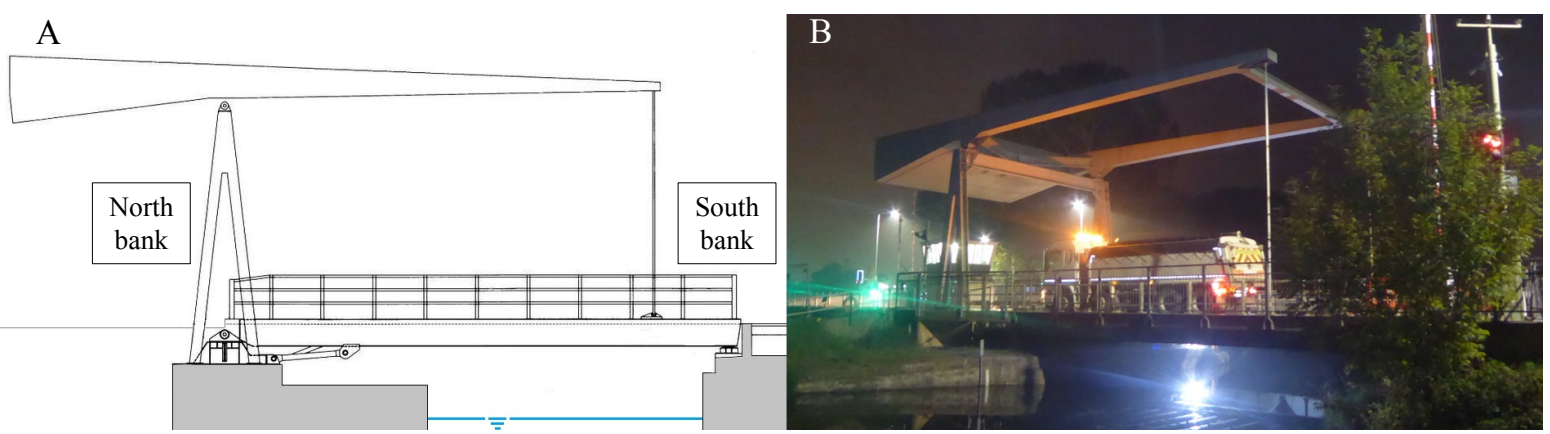

553 Figure 4 The Exeter Bascule Bridge: A) side elevation; B) photograph of a static load test.

\section{$554 \quad 4.2$ Model-class selection}

555 Three model parameters, influencing the most the structural behavior, were selected for model 556 updating: the equivalent Young's modulus of the aluminum deck $\left(\theta_{1}\right)$, the rotational stiffness 557 of the North-bank hinges $\left(\theta_{2}\right)$, and the axial stiffness of the hydraulic jacks $\left(\theta_{3}\right)$. Initial ranges 558 for each parameter are presented in Table 7. The axial stiffness of hydraulic jacks is used to 559 simulate their contribution as additional load-carrying supports. For the axial stiffness, the 560 lower bound considers two girders as simply supported at the abutments, while the upper bound 561 corresponds to the introduction of a semi-rigid support at jack connections.

562 Table 7 Model-parameter initial ranges for structural identification.

\begin{tabular}{cc}
\hline Parameters & Initial ranges \\
\hline$\theta_{1}$-Equivalent Young's modulus of aluminum deck $(\mathrm{GPa})$ & {$[60 ; 80]$} \\
$\theta_{2}$-Rotational stiffness of bearing devices $(\log (\mathrm{Nmm} / \mathrm{rad}))$ & {$[8 ; 12]$} \\
$\theta_{3}-$ Axial stiffness of hydraulic jacks $(\log (\mathrm{Nmm}))$ & {$[3 ; 5]$} \\
\hline
\end{tabular}

564 An initial population of 1000 model instances is generated from the uniform distribution of 565 each parameter value using Latin hypercube sampling [59]. For each load test, the same

566 population is used in order to generate predictions at sensor locations. Model uncertainties 
associated with the model class are presented in Table 8, while measurement uncertainties associated with the sensor types are presented in

569 Table 9. Uncertainties are estimated using sensor-provider information, engineering judgement 570 and heuristics. More information of the description of the model class and uncertainty 571 magnitudes could be found in [28].

572 Table 8 Estimations of model-class uncertainties.

\begin{tabular}{ccc}
\hline Uncertainty source & Uncertainty form & Uncertainty magnitude \\
\hline FE model simplification (\%) & Uniform & $-5 \% ;+20 \%$ \\
Mesh refinement (\%) & Uniform & $-1 \% ;+1 \%$ \\
Additional (\%) & Uniform & $-2 \% ;+2 \%$ \\
\hline
\end{tabular}

573

574 Table 9 Estimations of measurement uncertainties.

\begin{tabular}{ccc}
\hline Uncertainty source & Uncertainty form & Uncertainty magnitude \\
\hline & Sensor accuracy \\
\hline Camera $(\mathrm{mm})$ & Uniform & $-0.1 ;+0.1$ \\
Strain gauges $(\mu \varepsilon)$ & Uniform & $-2 ;+2$ \\
\hline & Measurement repeatability \\
\hline Camera $(\%)$ & Gaussian & $\mu=0 ; \sigma=1$ \\
Strain gauges $(\%)$ & Gaussian & $\mu=0 ; \sigma=1.5$ \\
\hline & Sensor installation \\
\hline Strain gauges $(\%)$ & Uniform & $-2 \% ;+2 \%$ \\
\hline
\end{tabular}

575

Load test 1

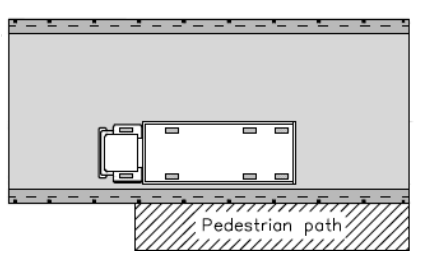

Load test 2

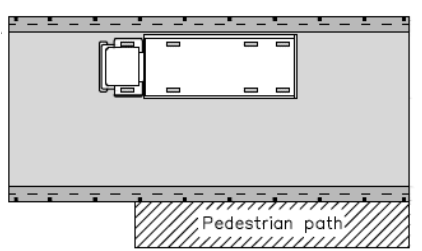

Load test 3

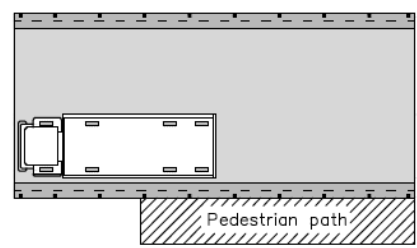

Load test 4

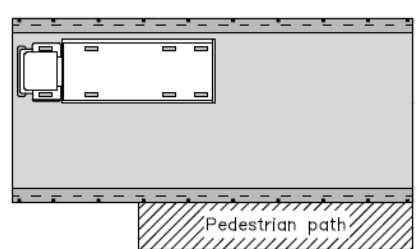

Load test 5
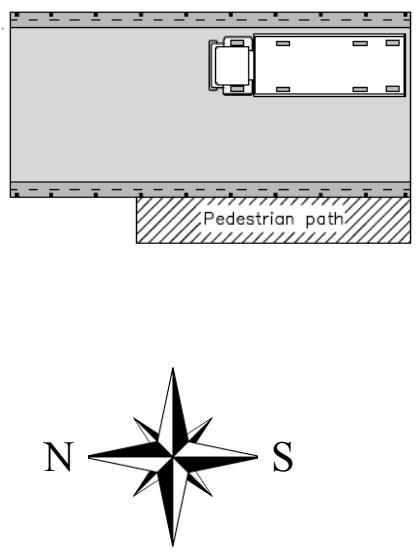

576

577

\section{8}

579

580

581

582

583

Figure 5 Possible static load tests.

\subsection{Monitoring-system characteristics}

Characteristics of the monitoring system include monitoring expenses and alternatives of possible sensor locations. The list of monitoring expenses is presented in Table 10. Load-test expenses include an initial cost for truck rental with driver and an additional cost per load test. Sensor costs depend on the sensor types (strain gauge and deflection measurement). In order to report measurements, a single base station and data-acquisition systems (every 4 sensors) 
must be rented. Main girders are directly accessible on both banks of the bridge. However, in the central area above the river (Figure 4), additional equipment is needed and professionals must be hired in order to install sensors, generating additional expenses for some sensor locations.

Table 10. List of monitoring expenses.

\begin{tabular}{ccc}
\hline Type of expense & Expense & Cost \\
\hline \multirow{2}{*}{ Load test } & Initial cost & $300[\mathrm{GBP}]$ \\
& Load test & $75[\mathrm{GBP} / \mathrm{LT}]$ \\
\hline \multirow{2}{*}{ Sensor } & Strain gauge & $400[\mathrm{GBP} / \mathrm{unit}]$ \\
& Deflection measurement & $300[\mathrm{GBP} / \mathrm{unit}]$ \\
\hline \multirow{2}{*}{ Data-reporting } & Base station & $500[\mathrm{GBP}]$ \\
system & Data-acquisition system & $500[\mathrm{GBP} / \mathrm{unit}]$ \\
\hline $\begin{array}{c}\text { Sensor installation } \\
\text { over the river }\end{array}$ & Additional equipment & $500[\mathrm{GBP}]$ \\
\hline
\end{tabular}

In order to generate predictions from the bridge finite-element model, possible sensor locations need to be defined according to the model class and installation constraints. Due to their small range of predictions, locations on secondary beams were not involved as possible locations. Two alternatives of possible sensor locations were chosen to consider additional costs of installation above the river (Figure 6). A discretization of possible sensor locations at every 0.95 meters, corresponding to the distance between secondary beams, was selected. In both alternatives, possible locations for strain gauges were chosen on top and bottom flanges (circles and triangles) on both girders. Bottoms of each girder were chosen as possible deflection-target locations (circles). To avoid local effects, sensor locations were chosen to start at $2 \mathrm{~m}$ from the supports. In the first alternative, possible sensor locations were chosen to be on the entire girders, creating 64 possible strain locations and 32 possible deflection locations. This alternative is called "Over the River" (OR) alternative because sensor locations can be selected over the river generating additional expenses. In the second alternative, no possible sensor locations were involved above the river (Figure 1), creating 32 possible strain locations and 16 possible deflection locations. This alternative is called "Not Over the River" (NOR) alternative. The performance comparison between measurement systems from the two alternatives will show if the information gained by installing sensors above the river is worth additional expenses. 
608

609

610

611

\section{2}

613

614

615

616

617

618

619

620

621

622

623

624

625

626

627

628

629

630
A

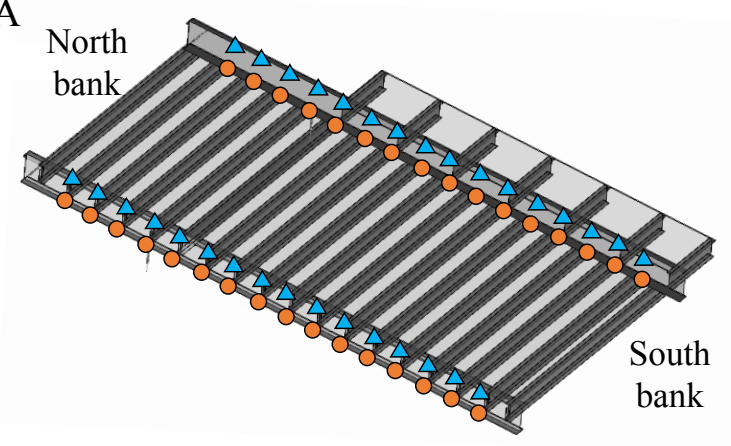

B

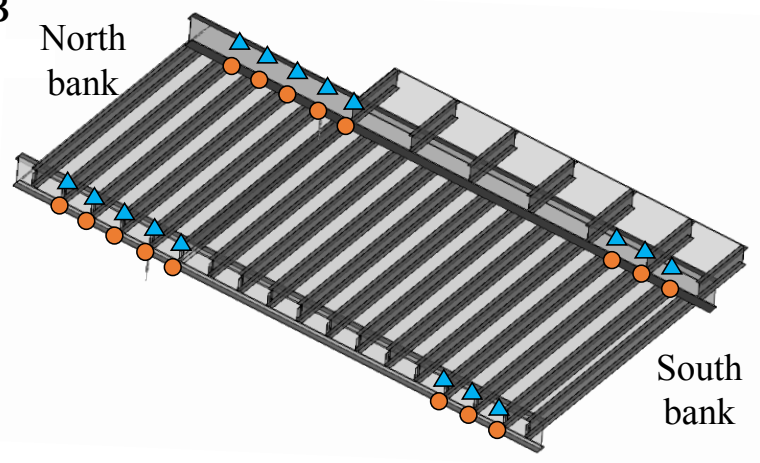

Figure 6. Possible sensor locations for two alternatives: A) Over the river (OR); B) Not over the river (NOR).

\section{Measurement-system recommendations}

In this Section, measurement-system recommendations according to the asset-manager preference settings are discussed. First, the information gained by possible measurement systems is assessed to reduce the set of options to consider in the MCDA. Then, options are evaluated independently for each remaining performance criterion. Eventually, the MCDA is performed to recommend a measurement system for each asset-manager preference setting.

\subsection{Information-gain assessment}

To define the set of options used in the MCDA, the information gain of measurement system is assessed using the hierarchical algorithm (Section 2.2). As mentioned in the case-study presentation (Section 4), two possible sensor-location sets (over river OR and not over river NOR) and the possibility to perform 1 to 5 load tests (LT) are taken into account. Therefore, the hierarchical algorithm for sensor placement must be run 10 times. The joint entropy is assessed as function of the number of sensors (Figure 7). The joint entropy increases significantly with number of sensors and number of load tests. For the same number of sensors and load tests, the difference in terms of joint entropy between the two alternatives of possible sensor locations (OR and NOR) is small. Measurement systems between 2 and 12 sensors and 1 to 5 load tests are considered in the set of possible options for the MCDA. Therefore, 110 options must be evaluated in the MCDA to find the recommended measurement system according to asset-manager-preference settings. 


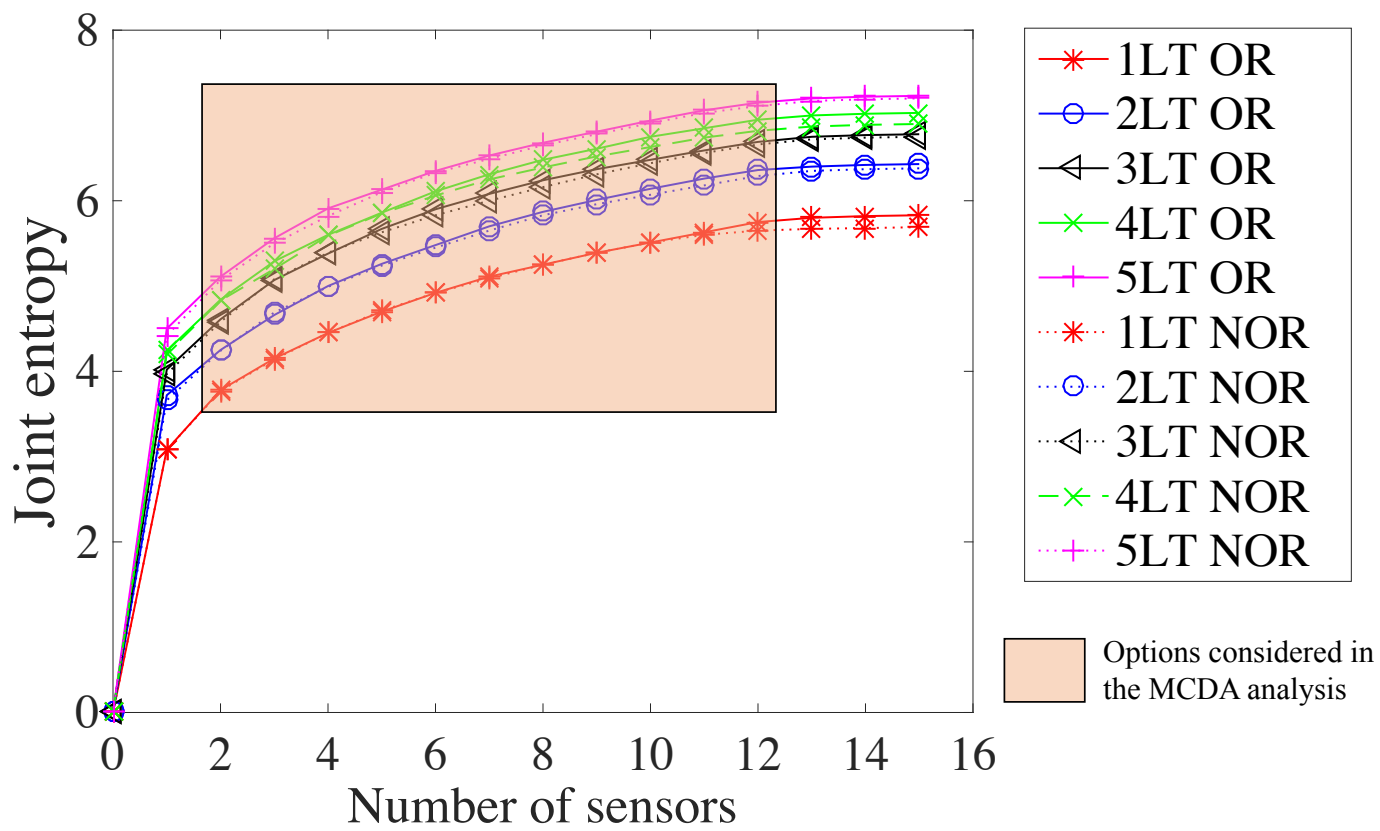

631

632

633

634

635

636

637

638

639

640

641

642

643

644

645

646

647

648

649

650

651

652

653

654

Figure 7. Information-gain assessment - through calculation of joint-entropy (Section 2.2) - of measurement systems as function of number of sensors for the two alternatives of possible sensor locations (OR and NOR) and the number of load tests (1LT to 5LT).

\subsection{Option assessment for remaining performance criteria}

Each measurement-system option is evaluated for each remaining performance criterion. Criterion metrics as function of number of sensors are presented in Figure 8. Figure 8A presents the cost of monitoring as function of number of sensors for 1 and 5 load tests (LT), representing lower and upper bounds of the cost of monitoring respectively. The cost of monitoring increases with increasing number of sensors and number of load tests. Figure 8B presents additional costs due to the installation of sensors above the river for the OR alternative of possible sensor locations. The cost of installation is nil as long as no sensor is installed above the river and increases when a new sensor is placed in the particular area. Figure $8 \mathrm{C}$ presents the ability to detect outliers in measurement once the bridge is monitored. The outlier detection ability increases with increasing number of sensors and is converging to the value of 0.99 for any number of load tests and alternative of possible sensor locations. Figure 8D presents the normalized loss of information in case of the failure of the best sensor. The loss of information decreases with increasing number of sensors and load tests. Except for the sensor-installation criterion (Figure $8 \mathrm{~B}$ ), criterion evaluations as function of number of sensors and load tests do not differ significantly between alternatives of possible sensor locations (OR and NOR). Additionally, it is observed that the cost of monitoring and sensor installation criteria are conflicting with the information gain (Figure 7), ability to detect outliers and robustness of information gain to sensor failure. To define quantitatively the optimal measurement system, a MCDA is thus required and will be presented in the following section. 

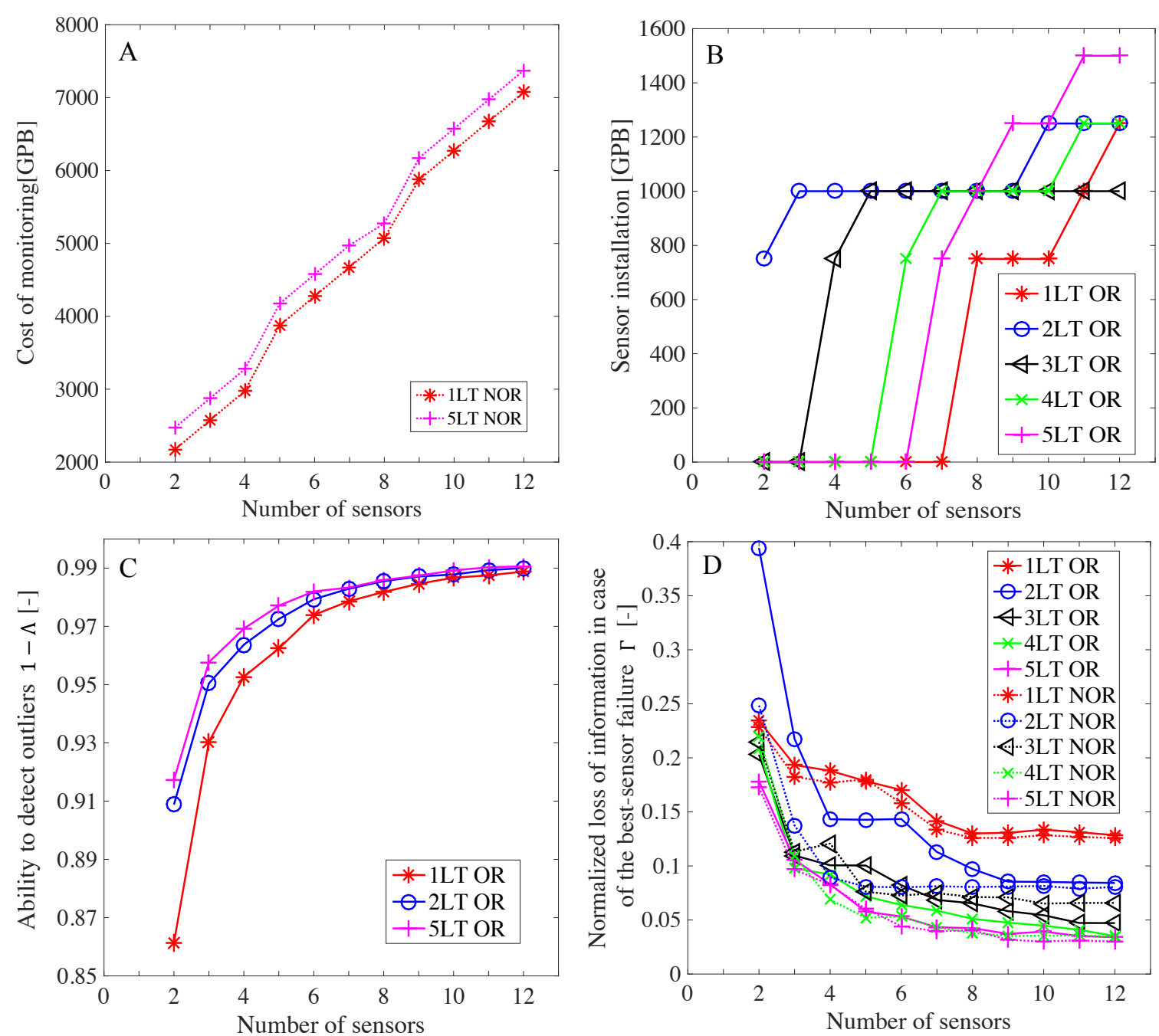

Figure 8. Measurement-system evaluations for each performance criterion as function of 657 number of sensors. A) Cost of monitoring; B) Sensor installation; C) Ability to detect outlier; 658 D) Normalized loss of information in case of the best-sensor failure.

\subsection{Measurement-system design according to asset-manager preference setting}

662 Once the set of options is evaluated for all measurement-system criteria (Section 5.2), the 663 comparison of measurement-system options is performed using the SMAA-PROMETHEE 664 (Section 3.2.1). Five settings of asset-manager preferences were presented in Section 3.2 (Table 665 5). Measurement-system recommendations are developed for each setting in this section. In 666 order to provide a rich guidance to the asset manager, metrics introduced in Phase 3 (Figure 1) 667 are used to recommend measurement systems.

668 For the sake of conciseness, options of measurement system are named as: alternative of sensor 669 locations - number of load tests - number of sensors. For instance, a measurement system 670 involving the alternative of possible sensor locations NOR, 5 load tests and 4 sensors is called 671 NOR-5-4.

672 The measurement system with the largest $1^{\text {st }}$-rank acceptability index $\left(\max _{a \in A} b^{1}(a)\right)$, i.e. the 673 highest frequency of an option being first, is presented for each setting of asset-manager 674 preference in Table 11 (Step 1, Figure 1). For each asset-manager preference setting, results in 
675 terms of measurement systems (alternative of possible locations (OR and NOR) Alt, number 676 of load tests $N_{\text {loadtest }}$ and number of sensors $N_{\text {sens }}$ ) with their respective $b^{1}$ (a) are shown. 677 Although the same alternative of possible locations (i.e. no sensors above the river) and the 678 same number of load tests (i.e. 5 load tests) are always selected, asset-manager preference 679 settings influence significantly the number of sensors to install on the bridge from 3 to 12 680 sensors. This result shows the ability of the framework to differentiate between measurement681 system options with conflicting performance criteria.

682 Comparing the ordinal (Settings 3 and 5) and cardinal (Settings 2 and 4) weighting-preference 683 types for the same preference scenario, recommended measurement systems are similar since 684 the difference is one sensor. However, $\max _{a \in A} b^{1}(a)$ differs significantly. For instance, between 685 settings 4 and $5, \max _{a \in A} b^{1}(a)$ equals to $87.9 \%$ and $25.1 \%$, respectively. This result shows that 686 the choice of the weighting-preference type influences the assessment of measurements system 687 using a MCDA.

688 Following Phase 3 (Figure 1), the recommended measurement system is clearly defined in case 689 the $\max _{a \in A} b^{1}(a)$ is large (i.e. $>70 \%$ ). This situation happens only for the setting 4 , which has a $690 \max _{a \in A} b^{1}(a)=87.9 \%$. Therefore, for this setting, it is not required to perform further 691 investigation to define the measurement-system recommendation. However, for other settings, 692 the maximum $\max _{a \in A} b^{1}(a)$ is lower than $70 \%$. Therefore, for these settings, measurement693 system recommendations are unclear as other measurement-system options may potentially 694 present similar $\max _{a \in A} b^{1}(a)$. Steps 2 to 4 of Phase 3 (Figure 1) are performed to provide guidance 695 to the asset manager in terms of measurement-system recommendations.

696 Table 11 Recommended measurement system - defined using an alternative of possible sensor 697 location $A l t$, a number of load tests $N_{\text {loadtest }}$ and a number of sensors $N_{\text {sens }}-$ with maximum 698 first-rank acceptability index $\max _{a \in A} b^{1}(a)$ according to the setting of asset-manager preferences $699-$ Step 1, Figure 1.

\begin{tabular}{|c|c|c|c|c|c|c|}
\hline \multirow{2}{*}{ Setting } & \multirow{2}{*}{$\begin{array}{l}\text { Preference } \\
\text { Scenario }\end{array}$} & \multirow{2}{*}{$\begin{array}{c}\text { Preference } \\
\text { type }\end{array}$} & \multicolumn{3}{|c|}{ Measurement system } & \multirow{2}{*}{$\begin{array}{c}\max _{a \in A} b^{1}(a) \\
{[\%]}\end{array}$} \\
\hline & & & Alt & $\mathrm{N}_{\text {loadtest }}$ & $\mathrm{N}_{\text {sens }}$ & \\
\hline 1 & Equal weight & Cardinal & NOR & 5 & 6 & 54.8 \\
\hline 2 & $\begin{array}{l}\text { Maximization of } \\
\text { information gain }\end{array}$ & Cardinal & NOR & 5 & 11 & 53.1 \\
\hline 3 & $\begin{array}{l}\text { Maximization of } \\
\text { information gain }\end{array}$ & Ordinal & NOR & 5 & 12 & 56.5 \\
\hline 4 & $\begin{array}{l}\text { Low-cost } \\
\text { monitoring }\end{array}$ & Cardinal & NOR & 5 & 4 & 87.9 \\
\hline 5 & $\begin{array}{l}\text { Low-cost } \\
\text { monitoring }\end{array}$ & Ordinal & NOR & 5 & 3 & 25.1 \\
\hline
\end{tabular}

In setting 1, the measurement system NOR-5-6 has the maximum first-rank acceptability index $\left(\operatorname{maxb}^{1}(\mathrm{NOR}-5-6)\right)$, which is equal to $54.8 \%$ (Table 11$)$. As this number is below $70 \%$ (Step 1, Figure 1), it is thus necessary to assess if other options are often the best solution in SMAA704 PROMETHEE simulations. In a setting with deterministic approach for weight (Table 4), the central weighing vector for an equal weight scenario remains constant at 0.2 . Nevertheless, the $b^{1}(a)$ of measurement-system options can be computed. Table 12 presents options with $b^{1}(a)$ equal or larger than $10 \%$. Four options are often ranked as the best solution. In these options, 708 the alternative of possible sensor locations NOR, and 5 load tests are always observed. 
However, measurement systems differ in terms of number of sensors, varying between 4 to 7 sensors. In the current setting, indifference and preference thresholds are the only MCDA parameters varying between SMAA-PROMETHEE simulations. It shows that these thresholds influence significantly the measurement-system rankings. Defining preference and indifference thresholds using bounds allows a constancy in measurement-system recommendations. Additionally, it justifies the choice of SMAA-PROMETHEE as the MCDA method. Although the $b^{1}$ (NOR-5-6) is clearly larger than other options (i.e. 54.8\% against $19.7 \%$ for the second-best option (NOR-5-7)), asset managers might be interested in further insights about the distribution of the option rankings as well as the pairwise performance to gain more confidence in their decision.

Table 13 presents three most frequent positions (MFPi) and their respective $b^{\text {MFPi }}$ (a) for these four options. NOR-5-6 and NOR-5-7 are the three first positions as most frequent positions, showing a clear preference of SMAA-PROMETHEE for these two options. A pairwise comparison shows that NOR-5-6 is preferred to NOR-5-4, NOR-5-5 and NOR-5-7 with a frequency of $88.9 \%, 83.6 \%$ and $72.5 \%$, respectively (Step 4, Phase 3, Figure 1). Following Steps 2-3-4 (Figure 1), the measurement system NOR-5-6 is preferred by the MCDA and is thus recommended for setting 1 .

Table 12 Measurement systems with first-rank acceptability indices $b^{1}(a)$ larger than $10 \%$ for setting 1 of asset-manager preferences - Step 2, Figure 1.

\begin{tabular}{cccc}
\hline \multicolumn{2}{c}{ Measurement system } & \multicolumn{1}{c}{$\mathbf{b}^{\mathbf{1}(\mathbf{a})}$} \\
\cline { 1 - 2 } Alt & $\mathrm{N}_{\text {loadtest }}$ & $\mathrm{N}_{\text {sens }}$ & {$[\%]$} \\
\hline NOR & 5 & 4 & 10.8 \\
NOR & 5 & 5 & 13.7 \\
NOR & 5 & 6 & 54.8 \\
NOR & 5 & 7 & 19.7 \\
\multicolumn{2}{c}{ Other options } & & 1.66 \\
\hline
\end{tabular}

Table 13 Three most frequent positions (MFPi) and their rank acceptability indices $b^{\text {MFPi }}$ (a) for best measurement systems of setting 1 of asset-manager preferences - Step 3, Figure 1.

\begin{tabular}{|c|c|c|c|c|c|c|c|c|}
\hline \multicolumn{3}{|c|}{ Measurement system } & \multirow{2}{*}{ MFP1 } & \multirow{2}{*}{$\mathbf{b}^{\mathrm{MPF1}}$ (a) } & \multirow{2}{*}{ MFP2 } & \multirow{2}{*}{$\mathbf{b}^{\mathrm{MPF}}(\mathbf{a})$} & \multirow{2}{*}{ MFP1 } & \multirow{2}{*}{$\mathbf{b}^{\mathrm{MPF} 3}$ (a) } \\
\hline Alt & $\mathrm{N}_{\text {loadtest }}$ & $\mathrm{N}_{\text {sens }}$ & & & & & & \\
\hline NOR & 5 & 4 & 7 & 12.3 & 1 & 10.8 & 6 & 10.2 \\
\hline NOR & 5 & 5 & 3 & 19.8 & 4 & 13.6 & 1 & 13.1 \\
\hline NOR & 5 & 6 & 1 & 54.8 & 2 & 26.6 & 3 & 12.2 \\
\hline NOR & 5 & 7 & 2 & 47.2 & 3 & 21.3 & 1 & 19.7 \\
\hline
\end{tabular}

Concerning Setting 2, the maximum $b^{1}$ (a) of a measurement system is equal to $53.1 \%$ (Table 11). Therefore, it is necessary to identify situations where other measurement systems perform frequently as the best solution. Table 14 presents the central weight vectors for each measurement system with $b^{1}(a)=10 \%$ or more. Only two options have a significant $b^{1}(a)$. Both measurement systems involve five load tests and the alternative of possible sensor locations NOR. However, they differ in terms of number of sensors between 11 and 12. NOR-5-11 and NOR-5-12 have similar ranking as $b^{1}$ (NOR-5-11) and $b^{1}$ (NOR-5-12) are equal to 53.1 and 41.9 $\%$ respectively. In addition, the central weight vectors are also very similar. This result shows that both options present similar results and the central weight vector and $b^{1}$ (a) could not help 
to differentiate them. A pairwise comparison and most-frequent-position analysis are thus needed. Table 15 presents three most frequent positions (MFPi) and their respective $b^{\text {MFPi }}$ (a) for the two options. Both options have the same three most frequent positions. As $b^{\text {MFPi }}$ (a) only slightly differ between the two options, this metric provides only limited support to differentiate these options in this situation. Eventually, in the pairwise comparison, NOR-5-11 is preferred in $58.1 \%$ to NOR-5-12, showing a slight preference of SMAA-PROMETHEE for this option (Step 4, Figure 1). This example shows that in case of options with similar results, SMAA-PROMETHEE provides metrics to define the recommended measurement system. In setting 2, the measurement system NOR-5-11 is thus recommended due to the pairwise comparison with NOR-5-12 (step 4, Figure 1).

Table 14 Central weight vector for measurement systems with first-rank acceptability index $b^{1}$ (a) more than $10 \%$ for setting 2 of asset-manager preferences - Step 2, Figure 1.

\begin{tabular}{|c|c|c|c|c|c|c|c|c|}
\hline \multicolumn{3}{|c|}{$\begin{array}{c}\text { Measurement } \\
\text { system }\end{array}$} & \multirow{2}{*}{$\begin{array}{r}\mathbf{b}^{1}(\mathbf{a}) \\
{[\%]}\end{array}$} & \multicolumn{5}{|c|}{ Central weight factors of measurement-system criterion } \\
\hline Alt & $\mathrm{N}_{\text {loadtest }}$ & $\mathrm{N}_{\text {sens }}$ & & $\begin{array}{l}\text { Info } \\
\text { gain }\end{array}$ & $\begin{array}{c}\text { Costs of } \\
\text { monitoring }\end{array}$ & $\begin{array}{c}\text { Outlier } \\
\text { detection }\end{array}$ & $\begin{array}{c}\text { Loss of } \\
\text { information }\end{array}$ & $\begin{array}{c}\text { Sensor } \\
\text { installation }\end{array}$ \\
\hline NOR & 5 & 11 & 53.1 & 0.391 & 0.133 & 0.176 & 0.175 & 0.125 \\
\hline NOR & 5 & 12 & 41.9 & 0.423 & 0.110 & 0.172 & 0.173 & 0.122 \\
\hline \multicolumn{3}{|c|}{ Other options } & 4.98 & - & - & - & - & - \\
\hline
\end{tabular}

Table 15 Three most frequent positions (MFPi) and their rank acceptability indices $b^{\text {MFPi }}$ (a) for best measurement systems of setting 2 of asset-manager preferences - Step 3, Figure 1.

\begin{tabular}{|c|c|c|c|c|c|c|c|c|}
\hline \multicolumn{3}{|c|}{ Measurement system } & \multirow{2}{*}{ MFP1 } & \multirow{2}{*}{$\mathbf{b}^{\text {MPF1 }}$ (a) } & \multirow{2}{*}{ MFP2 } & \multirow{2}{*}{$\mathbf{b}^{\text {MPF2 }}$ (a) } & \multirow{2}{*}{ MFP1 } & \multirow{2}{*}{$b^{\text {MPF3 }}$ (a) } \\
\hline Alt & $\mathrm{N}_{\text {loadtest }}$ & $\mathrm{N}_{\text {sens }}$ & & & & & & \\
\hline NOR & 5 & 11 & 1 & 53.1 & 2 & 44.8 & 3 & 1.02 \\
\hline NOR & 5 & 12 & 1 & 41.9 & 2 & 40.1 & 3 & 7.60 \\
\hline
\end{tabular}

756

757

758

759

760

761

762

763

764

765

766

767

768

769

770

771
As the highest $b^{1}$ (a) of a measurement system is equal to $56.5 \%$ (Table 11 ), it is necessary to assess when other measurement systems are frequently the best solution. Table 16 presents the central weight vector for each option with a $b^{1}(a)=10 \%$ or larger. Three options have a significant $b^{1}(a)$. However, NOR-5-12 has a clear preference of the SMAA-PROMETHEE analysis due to its larger $\mathrm{b}^{1}$ (a) compared with other options $(56.5 \%$ for NOR-5-12 compared to $18.5 \%$ for OR-5-12). However, as the central weight vector of best measurement systems differ significantly, this result shows a good example where asset managers may select a probabilistically-defined suboptimal measurement system in case of a polarization of their preferences. For instance, if they decide to attribute at least $50 \%$ of the criteria weight to the information-gain criterion, the solution OR-5-12 should be preferred.

Table 17 presents three most frequent positions (MFPi) and their respective $b^{\mathrm{MFPi}}$ (a) for the three options. NOR-5-12 is the only option with its most frequent position at the first three positions in sequential order. Additionally, in pairwise comparison, NOR-5-12 is preferred to NOR-5-11 and OR-5-12 with a frequency of $74.9 \%$ and $81.0 \%$, respectively. Therefore, according to Steps 3 to 4, NOR-5-12 is recommended as measurement system for setting 3 . 
Table 16 Central weight vector for measurement systems with a first-rank acceptability index

$b^{1}$ (a) more than $10 \%$ for setting 3 of asset-manager preferences - Step 2, Figure 1.

\begin{tabular}{|c|c|c|c|c|c|c|c|c|}
\hline \multicolumn{3}{|c|}{$\begin{array}{c}\text { Measurement } \\
\text { system }\end{array}$} & \multirow{2}{*}{$\begin{array}{r}\mathbf{b}^{1}(\mathbf{a}) \\
{[\%]}\end{array}$} & \multicolumn{5}{|c|}{ Central weight factors of measurement-system criterion } \\
\hline Alt & $\mathrm{N}_{\text {loadtest }}$ & $\mathrm{N}_{\text {sens }}$ & & $\begin{array}{l}\text { Info } \\
\text { gain }\end{array}$ & $\begin{array}{c}\text { Costs of } \\
\text { monitoring }\end{array}$ & $\begin{array}{c}\text { Outlier } \\
\text { detection }\end{array}$ & $\begin{array}{l}\text { Loss of } \\
\text { information }\end{array}$ & $\begin{array}{c}\text { Sensor } \\
\text { installation }\end{array}$ \\
\hline NOR & 5 & 11 & 13.7 & 0.369 & 0.136 & 0.183 & 0.249 & 0.063 \\
\hline NOR & 5 & 12 & 56.5 & 0.468 & 0.066 & 0.146 & 0.284 & 0.036 \\
\hline OR & 5 & 12 & 18.5 & 0.652 & 0.048 & 0.103 & 0.188 & 0.010 \\
\hline \multicolumn{3}{|c|}{ Other options } & 11.3 & - & - & - & - & - \\
\hline
\end{tabular}

Table 17 Three most frequent positions (MFPi) and their rank acceptability indices $b^{\text {MFPi }}$ (a) for

775 best measurement systems of setting 3 of asset-manager preferences - Step 3, Figure 1 .

\begin{tabular}{|c|c|c|c|c|c|c|c|c|}
\hline \multicolumn{3}{|c|}{ Measurement system } & \multirow{2}{*}{ MFP1 } & \multirow{2}{*}{$\mathbf{b}^{\mathrm{MPF} 1}(\mathbf{a})$} & \multirow{2}{*}{ MFP2 } & \multirow{2}{*}{$\mathbf{b}^{\mathrm{MPF} 2}(\mathbf{a})$} & \multirow{2}{*}{ MFP1 } & \multirow{2}{*}{$\mathbf{b}^{\mathrm{MPF} 3}(\mathbf{a})$} \\
\hline Alt & $\mathrm{N}_{\text {loadtest }}$ & $\mathrm{N}_{\text {sens }}$ & & & & & & \\
\hline NOR & 5 & 11 & 3 & 42.6 & 2 & 25.2 & 1 & 13.7 \\
\hline NOR & 5 & 12 & 1 & 56.5 & 2 & 25.8 & 3 & 5.01 \\
\hline OR & 5 & 12 & 2 & 33.8 & 1 & 18.5 & 3 & 15.1 \\
\hline
\end{tabular}

776

777

778

779

780

781

782

783

784

785

786

787

788

789

790

791

792
In Setting 4, a clear preference for a specific measurement system is observed as the $b^{1}$ (a) was equal to $87.9 \%$ (Table 11). According to the recommendation of Step 1 (Figure 1), it is not necessary to perform further investigation. However, for the purpose of an example the analysis proceeds as described below. Central weight vectors for each option with $b^{1}$ (a) equals to $10 \%$ or larger are presented in Table 18. Although two options present similar central weight vectors, NOR-5-4 is clearly preferred to NOR-5-3 in terms of first $b^{1}(a)$, as it is equal to $87.9 \%$ and $11.8 \%$ for NOR-5-4 and NOR-5-3, respectively. Additionally, Table 19 presents three most frequent positions (MFPi) and their respective $b^{\text {MFPi }}$ (a) for the two options. Only NOR-5-4 has the first position at the most frequent position, showing a preference for this measurement system. Eventually the pairwise comparison shows that NOR-5-4 is preferred to NOR-5-3 in $88.1 \%$ of SMAA-PROMETHEE simulations (Step 4, Figure 1). Based on Steps 1,3 and 4 (Figure 1), the measurement system NOR-5-4 is thus recommended for setting 4.

Table 18 Central weight vector for measurement systems with a first-rank acceptability index $b^{1}$ (a) more than $10 \%$ for setting 4 of asset-manager preferences - Step 2, Figure 1.

\begin{tabular}{|c|c|c|c|c|c|c|c|c|}
\hline \multicolumn{3}{|c|}{$\begin{array}{c}\text { Measurement } \\
\text { system }\end{array}$} & \multirow{2}{*}{$\begin{array}{r}b^{1}(\mathbf{a}) \\
{[\%]}\end{array}$} & \multicolumn{5}{|c|}{ Central weight factors of measurement-system criterion } \\
\hline Alt & $\mathrm{N}_{\text {loadtest }}$ & $\mathrm{N}_{\text {sens }}$ & & $\begin{array}{l}\text { Info } \\
\text { gain }\end{array}$ & $\begin{array}{c}\text { Costs of } \\
\text { monitoring }\end{array}$ & $\begin{array}{c}\text { Outlier } \\
\text { detection }\end{array}$ & $\begin{array}{c}\text { Loss of } \\
\text { information }\end{array}$ & $\begin{array}{c}\text { Sensor } \\
\text { installation }\end{array}$ \\
\hline NOR & 5 & 3 & 11.8 & 0.151 & 0.287 & 0.134 & 0.142 & 0.286 \\
\hline NOR & 5 & 4 & 87.9 & 0.180 & 0.281 & 0.130 & 0.130 & 0.281 \\
\hline \multicolumn{3}{|c|}{ Other options } & 0.316 & - & - & - & - & - \\
\hline
\end{tabular}


Table 19 Three most frequent positions (MFPi) and their rank acceptability indices $\mathrm{b}^{\mathrm{MFPi}}$ (a) for

794 best measurement systems of setting 4 of asset-manager preferences - Step 3, Figure 1.

\begin{tabular}{|c|c|c|c|c|c|c|c|c|}
\hline \multicolumn{3}{|c|}{ Measurement system } & \multirow{2}{*}{ MFP1 } & \multirow{2}{*}{$\mathbf{b}^{\mathrm{MPF} 1}$ (a) } & \multirow{2}{*}{ MFP2 } & \multirow{2}{*}{$\mathbf{b}^{\mathrm{MPF2}}$ (a) } & \multirow{2}{*}{ MFP1 } & \multirow{2}{*}{$\mathbf{b}^{\mathrm{MPF} 3}(\mathbf{a}$} \\
\hline Alt & $\mathrm{N}_{\text {loadtest }}$ & $\mathrm{N}_{\text {sens }}$ & & & & & & \\
\hline NOR & 5 & 3 & 3 & 48.7 & 2 & 34.7 & 1 & 11.8 \\
\hline NOR & 5 & 4 & 1 & 87.9 & 2 & 12.0 & 3 & 0.11 \\
\hline
\end{tabular}

795

796

797

798

799

800

801

802

803

804

805

806

807

808

809

810

811

812

813

814

815

816

817

For Setting 5, the measurement system NOR-5-4 has the highest $b^{1}(a)$, which is equal to $24.1 \%$ (Table 11). Therefore, a comparison with other measurement systems that are often ranked as best solution is needed. Table 20 presents the central weight vectors for each measurement system with a $b^{1}(a)$ equals to $10 \%$ or larger. Three options have a significant $b^{1}(a)$. Additionally, it is important to mention that many other options have been ranked as the best solution with low frequencies. This result can be explained by the ordinal choice in terms of weighting preference giving more freedom in terms of criteria weightings. Two options, NOR5-3 and NOR-5-4, present very similar $\mathrm{b}^{1}$ (a) (equal to $24.1 \%$ and $25.1 \%$ respectively), while NOR-4-2 has a lower $b^{1}$ (a) (equal to $12.2 \%$ ). For both options, central weight vectors differ significantly, especially in terms of weight for the costs of monitoring. This result shows a good example of a situation where asset managers may decide which option is the best measurement system according to their preferences in terms of criteria weight.

Table 21 presents three most frequent positions (MFPi) and their respective $b^{\mathrm{MFPi}}$ (a) for the three options. NOR-5-3 and NOR-5-4 are comparable in terms of MFPi. However, NOR-4-2 has a MFP1 at the $6^{\text {th }}$ rank, showing that this option is the best measurement system in specific cases and is generally suboptimal compared with NOR-5-3 or NOR-5-4. A pairwise comparison shows that NOR-5-4 is preferred to NOR-5-3 in $67.5 \%$ of the simulations, showing a preference of SMAA-PROMETHEE for this option. Therefore, based on Steps 3 and 4 (Figure 1), the measurement system NOR-5-3 is thus recommended for setting 5.

Table 20 Central weight vector for measurement systems with a first-rank acceptability index $b^{1}$ (a) larger than 10\% for setting 5 of asset-manager preferences - Step 2, Figure 1.

\begin{tabular}{|c|c|c|c|c|c|c|c|c|}
\hline \multicolumn{3}{|c|}{$\begin{array}{c}\begin{array}{c}\text { Measurement } \\
\text { system }\end{array} \\
\end{array}$} & \multirow{2}{*}{$\begin{array}{r}\mathbf{b}^{1}(\mathbf{a}) \\
{[\%]}\end{array}$} & \multicolumn{5}{|c|}{ Central weight factors of measurement-system criterion } \\
\hline Alt & $\mathrm{N}_{\text {loadtest }}$ & $\mathrm{N}_{\text {sens }}$ & & $\begin{array}{l}\text { Info } \\
\text { gain }\end{array}$ & $\begin{array}{c}\text { Costs of } \\
\text { monitoring }\end{array}$ & $\begin{array}{c}\text { Outlier } \\
\text { detection }\end{array}$ & $\begin{array}{c}\text { Loss of } \\
\text { information }\end{array}$ & $\begin{array}{c}\text { Sensor } \\
\text { installation }\end{array}$ \\
\hline NOR & 4 & 2 & 12.2 & 0.093 & 0.570 & 0.035 & 0.074 & 0.228 \\
\hline NOR & 5 & 3 & 24.1 & 0.145 & 0.459 & 0.043 & 0.098 & 0.256 \\
\hline NOR & 5 & 4 & 25.1 & 0.216 & 0.337 & 0.056 & 0.123 & 0.267 \\
\hline \multicolumn{3}{|c|}{ Other options } & 36.6 & - & - & - & - & - \\
\hline
\end{tabular}


818 Table 21 Three most frequent positions (MFPi) and their rank acceptability indices $\mathrm{b}^{\mathrm{MFPi}}$ (a) for

819 best measurement systems of setting 5 of asset-manager preferences - Step 3, Figure 1.

\begin{tabular}{cccccccccc}
\hline \multicolumn{2}{c}{ Measurement system } & \multirow{2}{*}{ MFP1 } & \multirow{2}{*}{$\mathbf{b}^{\text {MPF1 }}(\mathbf{a})$} & \multirow{2}{*}{ MFP2 } & $\mathbf{b}^{\text {MPF2 }}(\mathbf{a})$ & \multirow{2}{*}{ MFP1 } & $\mathbf{b}^{\text {MPF3 }}(\mathbf{a})$ \\
\hline Alt & $\mathrm{N}_{\text {loadtest }}$ & $\mathrm{N}_{\text {sens }}$ & & & & & & & \\
NOR & 4 & 2 & 6 & 16.5 & 3 & 13.7 & 1 & 12.2 \\
NOR & 5 & 3 & 1 & 26.1 & 4 & 20.3 & 2 & 19.8 \\
NOR & 5 & 4 & 1 & 25.1 & 2 & 7.83 & 8 & 7.57 \\
\hline
\end{tabular}

820

\subsection{Comparison of optimal measurement systems}

822 In this section, the recommended measurement systems defined for each setting of asset823 manager preferences (Table 11) are compared. Results are summarized in Figure 9, where 824 measurement-system recommendations are presented. For all weighting scenarios, the 825 alternative of possible locations NOR is selected, meaning that sensors should not be installed 826 over the river. Over-the-river sensor locations require additional costs for the installation 827 (Figure 8B) and generate only slight increases of information gain (Figure 7). Due to the small 828 influence on the cost of monitoring (Figure 8A) but significant influence on the information 829 gain (Figure 7), the option to perform five load tests were selected for all weighting preference 830 settings. However, recommended measurement systems differ significantly in terms of number 831 of sensors from 3 sensors for the setting 5 (Figure 9E) involving a low-cost monitoring to 12 832 sensors for the setting 2 (Figure 9B), where an asset manager prefers to maximize the 833 information gain. Therefore, the choice of number of sensors is drastically influenced by the 834 asset-manager preference settings. This result shows that the proposed framework for measurement-system design supports asset managers in terms of optimal measurement-system recommendation.

Regarding the sensor configuration for each setting of asset-manager preferences, most sensors are placed between the hydraulic jack and the North-bank bearing devices. As these elements are the location of the two most important model parameters to identify in the structural identification (Section 4.2), it shows that optimal sensor locations are strongly influenced by the model class selection. This highlights the importance of the initial task definition (Section 4.1). Due to the transversally asymmetrical load tests (Figure 5), sensors were placed on the side where most load tests will be performed as measurements will have a larger signal-tonoise ratio. The deflection target is only placed in settings 2 and 3, involving scenarios of a maximization of the information gain. As sensor locations are selected sequentially by the hierarchical algorithm, it shows that this sensor was chosen lately. This sensor is less powerful than strain gauges due to its relative large measurement uncertainties (Table 8). 


\section{A) Setting 1}

Asset-manager preferences

Preference scenario: Equal weight

Preference type: Cardinal

Recommended measurement system

Alternative of possible sensor location: NOR

Number of load tests: 5

Number of sensors: 6

Sensor configuration

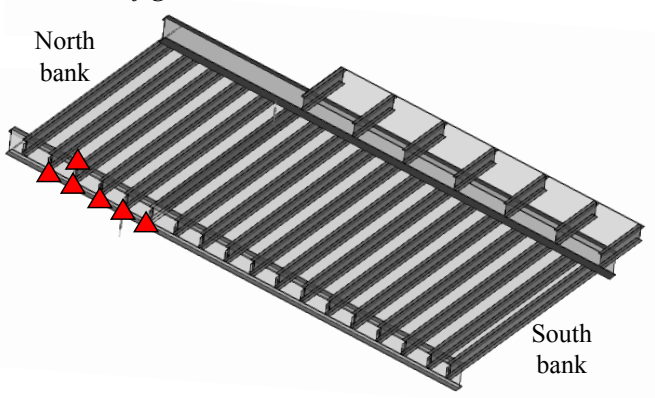

C) Setting 3

Asset-manager preferences

Preference scenario: Maximization information gain Preference type: Ordinal

Recommended measurement system

Alternative of possible sensor location: NOR

Number of load tests: 5

Number of sensors: 12

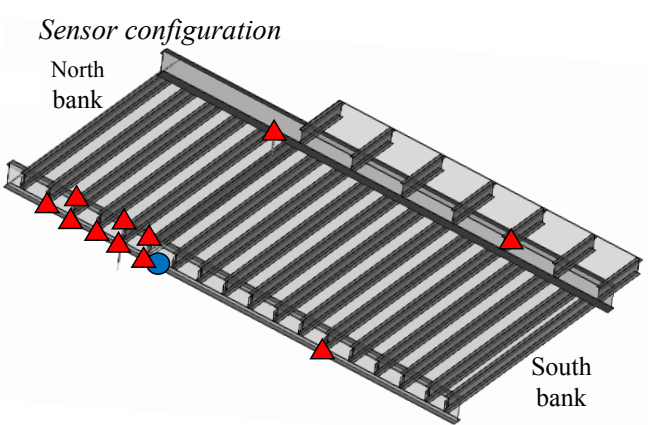

\section{E) Setting 5}

Asset-manager preferences

Preference scenario: Low-cost monitoring

Preference type: Ordinal

Recommended measurement system

Alternative of possible sensor location: NOR

Number of load tests: 5

Number of sensors: 3

Sensor configuration

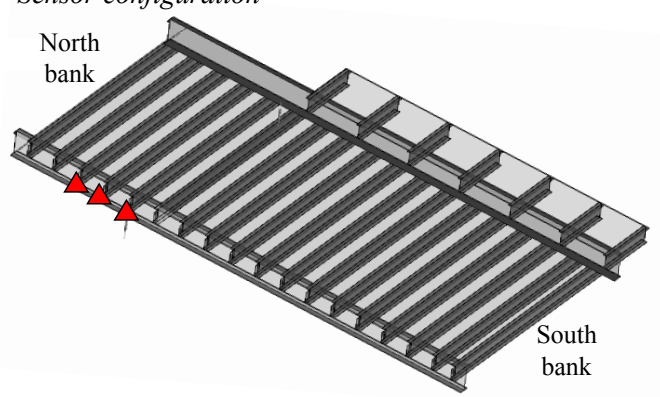

\section{B) Setting 2}

Asset-manager preferences

Preference scenario: Maximization information gain Preference type: Cardinal

Recommended measurement system

Alternative of possible sensor location: NOR

Number of load tests: 5

Number of sensors: 11

Sensor configuration

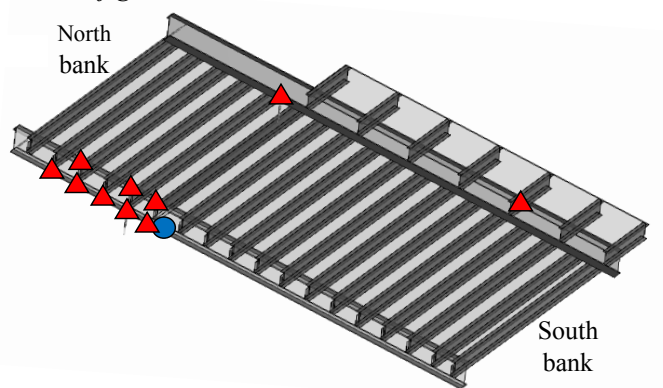

\section{D) Setting 4}

Asset-manager preferences

Preference scenario: Low-cost monitoring Preference type: Cardinal

Recommended measurement system

Alternative of possible sensor location: NOR

Number of load tests: 5

Number of sensors: 4

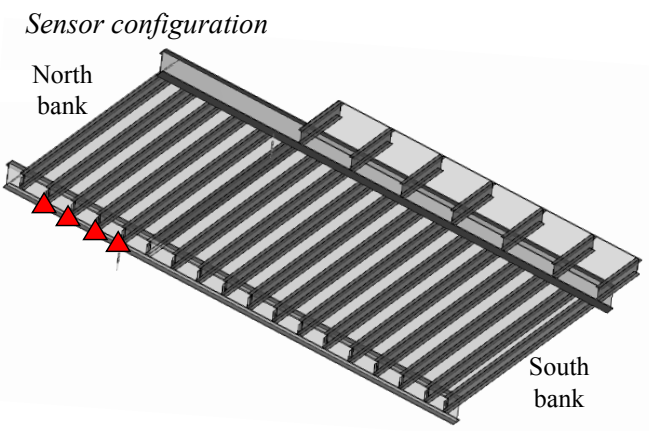

Figure 9 Recommended measurement systems according to asset-manager preference scenarios. A) Setting 1; B) Setting 2; C) Setting 3; D) Setting 4; E) Setting 5. 
852 In the present study, a MCDA framework is proposed to support asset-manager decision making in terms of measurement-system design. Once a model-class is selected, an information-gain assessment using the joint-entropy metric is performed to reduce the set of possible measurement systems. Then, measurement systems are assessed using five performance criteria: information gain, costs of monitoring, ability to detect outliers, loss of information in case of sensor failure, sensor installation. The metrics, probabilistic best solution, most frequent rank positions and pairwise comparison offer information-rich guidance to assist asset managers in terms of recommended measurement systems. The applicability of the framework was demonstrated using a full-scale case study and covering several scenarios of asset-manager preferences. When preference settings are compared, recommended measurement-systems differ in terms of number of sensors but lead to similar conclusions in terms of number of load tests and alternatives of sensor locations. Traditional approaches used in practical applications of measurement-system design involve comparison of the information gain with the cost of monitoring in terms of the number of sensors (Figure 10). As these measurement-system criteria are conflicting, an asset manager chooses the number of sensors implicitly according to some weighting of preferences. As shown in Figure 10, the information-gain (joint entropy) function is parabolic with respect to the number of sensors while the cost function is linear. It is thus an ambiguous task to define the optimal number of sensors. For instance, for a scenario where the information gain is preferred to the cost of monitoring, an asset manager may argue that 12 or more sensors are the best choice while a more cost-conscious manager may prefer 8 sensors. The use of a quantitative multi-criteria framework for measurement-system design has potential for more comprehensive decision support.
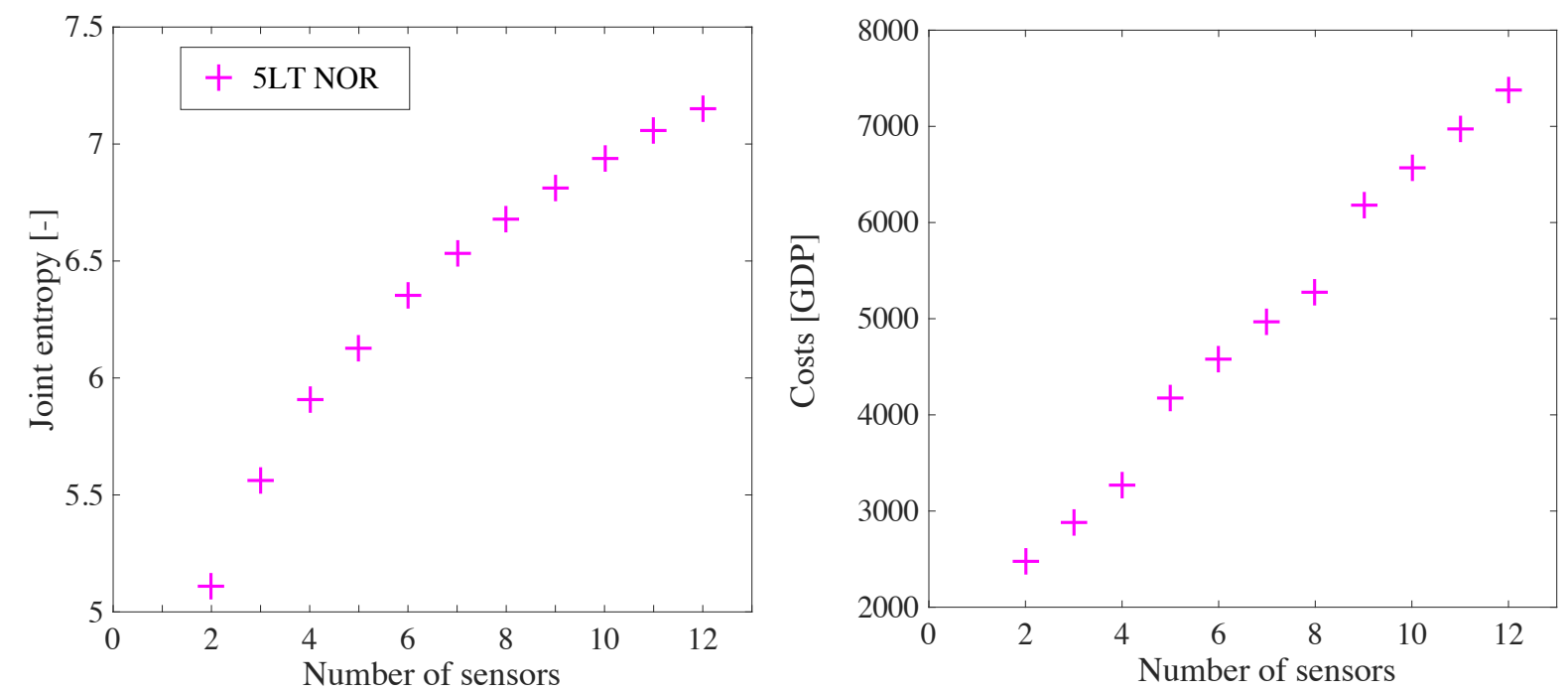

Figure 10 Comparison between cost of monitoring and information gain (joint entropy) assessed using joint entropy - as function of number of sensors for alternatives of measurement system considering 5 load tests (5LT) with the "not over the river" alternative (NOR) of possible sensor locations.

The framework for measurement-system design, proposed in this study, has several advantages when compared with other MCDA methods used in the structural-identification field [26], [60], [61] (Table 22). First, the proposed framework is able to accommodate ordinal and cardinal importance orders of preferences, making the framework flexible for asset managers. Then, in order to compare possible measurement systems, the framework provides metrics such as 
885

886

887

888

889

890

891

892

893

894

895

896

897

898

899

900

901

902

903

904

905

906

907

908

909

910

911

912

913

914

915

916

917

918

option ranking and pairwise comparison, thus avoiding that good measurement-system designs are proposed using a "blackbox". Additionally, measurement-system recommendations may be sensitive to MCDA parameters, such as criteria weighting and preference functions. Appropriate selection is a difficult task for asset managers. The framework proposed in this paper allows the use of bounds for MCDA-parameter definitions (Table 4, Table 6). This allows a more engineer-friendly approach for measurement-system design and provides robust (hence credible) recommendations with respect to MCDA-parameter variations.

Table 22 Comparison of MCDA methods used in structural identification.

\begin{tabular}{ccccc}
\hline MCDA & \multicolumn{2}{c}{$\begin{array}{c}\text { Asset-manager } \\
\text { preferences }\end{array}$} & \multicolumn{2}{c}{$\begin{array}{c}\text { Measurement-system } \\
\text { comparison }\end{array}$} \\
\cline { 2 - 5 } method & Ordinal & Cardinal & $\begin{array}{c}\text { Multi-metric } \\
\text { recommendation }\end{array}$ & $\begin{array}{c}\text { Robustness to MCDA } \\
\text { parameter variations }\end{array}$ \\
\hline Traditional & & $\checkmark$ & & \\
PROMETHEE [61] & & $\checkmark$ & & $\checkmark$ \\
Traditional & & & $\checkmark$ & \\
weighted sum [60] & & $\checkmark$ & & \\
RR-Pareto [26] & $\checkmark$ & $\checkmark$ & & \\
This paper & $\checkmark$ & $\checkmark$ & & \\
\hline
\end{tabular}

The following limitations of the work are recognized. Model-class definitions, including model-parameter choice and uncertainty estimations, influence evaluations of performance criteria such as information gain, outlier detection and robustness of information gain to sensor failure. The greedy-search strategy that is used in the hierarchical algorithm to define possible options does not necessarily lead to a global optimum of the joint entropy, particularly for small numbers of sensors. As the solution space is reduced using the information-gain criterion, measurement systems compared in MCDA may not always lie on the Pareto front of the solution space.

The success of any measurement-system-design methodology based on a model-based strategy depends on the quality of the numerical model used to predict structural behavior. A reliable model is important to obtain a representative range of predictions at possible sensor locations. Prior to measurement-system design, visual inspection is required to validate model assumptions.

\section{Conclusions}

A quantitative strategy for measurement-system design increases the performance of the structural-identification method by enhancing the discrimination between good and bad model instances. Following development of the approach on a full-scale test case, specific conclusions of the study are:

- A multi-criteria approach for measurement system design leads to more informed decision making, especially when performance criteria that are in addition to typical metrics of information gain and cost of monitoring are included

- The MCDA methodology supports quantitatively the rational selection of measurement systems even if there is no clear dominance amongst options. Recommendations are supported for multiple sets of constraints on the weighting of preferences and through comparison of measurement systems 
- The tiered strategy supports an informed selection of good measurement system designs according to asset-manager preferences by providing a complete set of preferred alternatives, including the best solution defined probabilistically and specific situations when other near-optimal solutions might be preferred

Future work will focus on the combination of expected information gained by static and dynamic tests to support sensor-system design for structural identification. Additionally, a framework will be developed to evaluate the influence of measurement-system-design methodologies on asset management that is based on the value of information and reservecapacity assessment.

\section{Acknowledgements}

929 The research was conducted at the Future Cities Laboratory and Future Resilient Systems at 930 the Singapore-ETH Centre, which was established collaboratively between ETH Zurich and 931 Singapore's National Research Foundation (FI 370074011-370074016) under its Campus for 932 Research Excellence and Technological Enterprise programme. The authors gratefully acknowledge the University of Exeter (J. Brownjohn, P. Kripakaran and the Full Scale Dynamics Ltd. [UK]) for support during load tests in the scope of the case study. Salvatore Corrente acknowledges the funding by the FIR of the University of Catania BCAEA3 and by the Department of Economics and Business of the University of Catania. Additionally, the authors are thankful to S. Greco for valuable input.

\section{Conflict of interest}

939 The authors declare that they have no conflict of interest.

\section{References}

[1] World Economic Forum, "Strategic infrastructure, steps to operate and maintain infrastructure efficiently and effectively," World Economic Forum, Davos, 180314, 2014.

[2] I. F. C. Smith, "Studies of Sensor Data interpretation for Asset Management of the Built environment," Front. Built Environ., vol. 2, pp. 2-8, 2016.

[3] F. Catbas, T. Kijewski-Correa, T. Lynn, and A. Aktan, Structural identification of constructed systems. American Society of Civil Engineers, 2013.

[4] J. E. Mottershead and M. I. Friswell, "Model updating in structural dynamics: a survey," J. Sound Vib., vol. 167, no. 2, pp. 347-375, 1993.

[5] J. L. Beck and S.-K. Au, "Bayesian updating of structural models and reliability using Markov chain Monte Carlo simulation," J. Eng. Mech., vol. 128, no. 4, pp. 380-391, 2002.

[6] J. E. Mottershead, M. Link, and M. I. Friswell, "The sensitivity method in finite element model updating: a tutorial," Mech. Syst. Signal Process., vol. 25, no. 7, pp. 2275-2296, 2011.

[7] J. L. Beck and L. S. Katafygiotis, "Updating models and their uncertainties. I: Bayesian statistical framework," J. Eng. Mech., vol. 124, no. 4, pp. 455-461, 1998.

[8] L. S. Katafygiotis and J. L. Beck, "Updating models and their uncertainties. II: Model identifiability," J. Eng. Mech., vol. 124, no. 4, pp. 463-467, 1998.

[9] R. Pasquier, J.-A. Goulet, C. Acevedo, and I. F. C. Smith, "Improving fatigue evaluations of structures using in-service behavior measurement data," J. Bridge Eng., vol. 19, no. 11, p. 04014045, 2014. 
[10] B. Raphael and I. F. C. Smith, "Finding the right model for bridge diagnosis," Artif. Intell. Struct. Eng., pp. 308-319, 1998.

[11] Y. Robert-Nicoud, B. Raphael, O. Burdet, and I. F. C. Smith, "Model identification of bridges using measurement data," Comput. Civ. Infrastruct. Eng., vol. 20, no. 2, pp. 118 $131,2005$.

[12] J.-A. Goulet and I. F. C. Smith, "Structural identification with systematic errors and unknown uncertainty dependencies," Comput. Struct., vol. 128, pp. 251-258, 2013.

[13] M. Proverbio, D. G. Vernay, and I. F. C. Smith, "Population-based structural identification for reserve-capacity assessment of existing bridges," J. Civ. Struct. Health Monit., pp. 1-20, Apr. 2018.

[14] D. G. Vernay, F.-X. Favre, and I. F. C. Smith, "Robust model updating methodology for estimating worst-case load capacity of existing bridges," J. Civ. Struct. Health Monit., pp. $1-18,2018$.

[15] E. Heredia-Zavoni and L. Esteva, "Optimal instrumentation of uncertain structural systems subject to earthquake ground motions," Earthq. Eng. Struct. Dyn., vol. 27, no. 4, pp. 343-362, 1998.

[16] F. E. Udwadia, "Methodology for optimum sensor locations for parameter identification in dynamic systems," J. Eng. Mech., vol. 120, no. 2, pp. 368-390, 1994.

[17] C. Papadimitriou, "Pareto optimal sensor locations for structural identification," Comput. Methods Appl. Mech. Eng., vol. 194, no. 12, pp. 1655-1673, 2005.

[18] C. Papadimitriou, J. L. Beck, and S.-K. Au, "Entropy-based optimal sensor location for structural model updating," J. Vib. Control, vol. 6, no. 5, pp. 781-800, 2000.

[19] Y. Robert-Nicoud, B. Raphael, and I. F. C. Smith, "Configuration of measurement systems using Shannon's entropy function," Comput. Struct., vol. 83, no. 8, pp. 599-612, 2005.

[20] P. Kripakaran and I. F. C. Smith, "Configuring and enhancing measurement systems for damage identification," Adv. Eng. Inform., vol. 23, no. 4, pp. 424-432, 2009.

[21] D. C. Kammer, "Sensor set expansion for modal vibration testing," Mech. Syst. Signal Process., vol. 19, no. 4, pp. 700-713, 2005.

[22] M. Papadopoulou, B. Raphael, I. F. C. Smith, and C. Sekhar, "Hierarchical sensor placement using joint entropy and the effect of modeling error," Entropy, vol. 16, no. 9, pp. 5078-5101, 2014.

[23] N. J. Bertola, M. Papadopoulou, D. G. Vernay, and I. F. C. Smith, "Optimal multi-type sensor placement for structural identification by static-load testing," Sensors, vol. 17, no. 12, p. 2904, 2017.

[24] J.-A. Goulet and I. F. C. Smith, "Performance-driven measurement system design for structural identification,” J. Comput. Civ. Eng., vol. 27, no. 4, pp. 427-436, 2012.

[25] R. Pasquier, J.-A. Goulet, and I. F. C. Smith, "Measurement system design for civil infrastructure using expected utility," Adv. Eng. Inform., vol. 32, pp. 40-51, 2017.

[26] M. Papadopoulou, B. Raphael, I. F. C. Smith, and C. Sekhar, "Evaluating predictive performance of sensor configurations in wind studies around buildings," Adv. Eng. Inform., vol. 30, no. 2, pp. 127-142, 2016.

[27] N. J. Bertola and I. F. C. Smith, "Adaptive Approach for Sensor Placement Combining a Quantitative Strategy with Engineering Practice," in Advanced Computing Strategies for Engineering, 2018, pp. 210-231.

[28] M. Proverbio, N. J. Bertola, and I. F. C. Smith, "Outlier-Detection Methodology for Structural Identification Using Sparse Static Measurements,” Sensors, vol. 18, no. 6, p. 1702, May 2018.

[29] L. Sela and S. Amin, "Robust sensor placement for pipeline monitoring: Mixed integer and greedy optimization," Adv. Eng. Inform., vol. 36, pp. 55-63, Apr. 2018. 
1012

1013

1014

1015

1016

1017

1018

1019

1020

1021

1022

1023

1024

1025

1026

1027

1028

1029

1030

1031

1032

1033

1034

1035

1036

1037

1038

1039

1040

1041

1042

1043

1044

1045

1046

1047

1048

1049

1050

1051

1052

1053

1054

1055

1056

1057

1058

1059

1060

[30] E. K. Zavadskas, J. Antuchevičienè, and O. Kapliński, "Multi-criteria decision making in civil engineering. Part II-applications," Eng. Struct. Technol., vol. 7, no. 4, pp. 151-167, 2015.

[31] E. K. Zavadskas, J. Antuchevičienè, and O. Kapliński, "Multi-criteria decision making in civil engineering: Part I - a state-of-the-art survey," Eng. Struct. Technol., vol. 7, no. 3, pp. 103-113, Jul. 2015.

[32] S. Greco, J. Figueira, and M. Ehrgott, Multiple criteria decision analysis: State of the Art Surveys. Springer, 2016.

[33] M. Cinelli, "The Art of Supporting Decision-Making," Exch. Interdiscip. Res. J., no. 2, pp. 298-308\%V 4, 2017.

[34] J.-P. Brans and Y. De Smet, "PROMETHEE Methods," in Multiple Criteria Decision Analysis: State of the Art Surveys, S. Greco, M. Ehrgott, and J. R. Figueira, Eds. New York, NY: Springer New York, 2016, pp. 187-219.

[35] J. Figueira, S. Greco, B. Roy, and R. Słowiński, "An overview of ELECTRE methods and their recent extensions," J. Multi-Criteria Decis. Anal., vol. 20, pp. 61-85, Apr. 2013.

[36] J. S. Dyer, "Multiattribute utility theory (MAUT). In: Greco, S., Ehrgott, M., Figuiera, J.R. (eds.): Multiple Criteria Decision Analysis: State of the art surveys," Int. Ser. Oper. Res. Manag. Sci., vol. 233, pp. 285-314, 2016.

[37] R. L. Keeney and H. Raiffa, Decisions with multiple objectives: preferences and value trade-offs. Cambridge university press, 1993.

[38] R. Lahdelma, J. Hokkanen, and P. Salminen, "SMAA - Stochastic multiobjective acceptability analysis," Eur. J. Oper. Res., vol. 106, no. 1, pp. 137-143, Apr. 1998.

[39] S. Corrente, J. R. Figueira, and S. Greco, "The SMAA-PROMETHEE method," Eur. J. Oper. Res., vol. 239, no. 2, pp. 514-522, Dec. 2014.

[40] S. Corrente, J. R. Figueira, S. Greco, and R. Słowiński, "A robust ranking method extending ELECTRE III to hierarchy of interacting criteria, imprecise weights and stochastic analysis," Omega, vol. 73, pp. 1-17, Dec. 2017.

[41] S. Angilella, S. Corrente, and S. Greco, "Stochastic multiobjective acceptability analysis for the Choquet integral preference model and the scale construction problem," Eur. J. Oper. Res., vol. 240, no. 1, pp. 172-182, 2015.

[42] M. Kadziński et al., "Co-constructive development of a green chemistry-based model for the assessment of nanoparticles synthesis," Eur. J. Oper. Res., vol. 264, no. 2, pp. 472490, Jan. 2018.

[43] Y. Robert-Nicoud, B. Raphael, and I. F. C. Smith, "System identification through model composition and stochastic search," J. Comput. Civ. Eng., vol. 19, no. 3, pp. 239-247, 2005.

[44] R. Pasquier and I. F. C. Smith, "Iterative structural identification framework for evaluation of existing structures," Eng. Struct., vol. 106, pp. 179-194, 2016.

[45] E. Reynders, G. Wursten, and G. De Roeck, "Output-only structural health monitoring in changing environmental conditions by means of nonlinear system identification," Struct. Health Monit., vol. 13, no. 1, pp. 82-93, Oct. 2013.

[46] V. Belton and T. Stewart, "Problem Structuring and Multiple Criteria Decision Analysis," in Trends in Multiple Criteria Decision Analysis, vol. 142, M. Ehrgott, J. R. Figueira, and S. Greco, Eds. Boston, MA: Springer US, 2010, pp. 209-239.

[47] B. Raphael, "Multi-criteria decision making for collaborative design optimization of buildings," Built Environ. Proj. Asset Manag., vol. 1, no. 2, pp. 122-136, 2011.

[48] B. Roy, J. Figueira, and J. Almeida Dias, "Discriminating thresholds as a tool to cope with imperfect knowledge in multiple criteria decision aiding: Theoretical results and practical issues," Omega, vol. 43, pp. 9-20, 2014. 
1061

1062

1063

1064

1065

1066

1067

1068

1069

1070

1071

1072

1073

1074

1075

1076

1077

1078

1079

1080

1081

1082

1083

1084

1085

1086

1087

1088

1089

1090

1091

1092

1093

1094

1095

1096

1097

1098

1099

[49] B. Roy, "Robustness in operational research and decision aiding: A multi-faceted issue," Eur. J. Oper. Res., vol. 200, no. 3, pp. 629-638, 2010.

[50] J. C. Cegan, A. M. Filion, J. M. Keisler, and I. Linkov, "Trends and applications of multicriteria decision analysis in environmental sciences: literature review," Environ. Syst. Decis., vol. 37, no. 2, pp. 123-133, Jun. 2017.

[51] M. Cinelli, S. R. Coles, and K. Kirwan, "Analysis of the potentials of multi criteria decision analysis methods to conduct sustainability assessment," Ecol. Indic., vol. 46, pp. 138-148, Nov. 2014.

[52] L. Diaz-Balteiro, J. González-Pachón, and C. Romero, "Measuring systems sustainability with multi-criteria methods: A critical review," Eur. J. Oper. Res., vol. 258, no. 2, pp. 607-616, Apr. 2017.

[53] H. V. Rowley, G. M. Peters, S. Lundie, and S. J. Moore, "Aggregating sustainability indicators: Beyond the weighted sum," J. Environ. Manage., vol. 111, pp. 24-33, Nov. 2012.

[54] J.-P. Brans and P. Vincke, "Note-A Preference Ranking Organisation Method: (The PROMETHEE Method for Multiple Criteria Decision-Making)," Manag. Sci., vol. 31, no. 6, pp. 647-656, 1985.

[55] S. G. Arcidiacono, S. Corrente, and S. Greco, "GAIA-SMAA-PROMETHEE for a hierarchy of interacting criteria," Eur. J. Oper. Res., vol. 270, no. 2, pp. 606-624, Oct. 2018.

[56] M. Behzadian, R. B. Kazemzadeh, A. Albadvi, and M. Aghdasi, "PROMETHEE: A comprehensive literature review on methodologies and applications," Eur. J. Oper. Res., vol. 200, no. 1, pp. 198-215, 2010.

[57] S. Angilella, P. Catalfo, S. Corrente, A. Giarlotta, S. Greco, and M. Rizzo, "Robust sustainable development assessment with composite indices aggregating interacting dimensions: The hierarchical-SMAA-Choquet integral approach," Knowl.-Based Syst., vol. 158, pp. 136-153, Oct. 2018.

[58] S. Corrente, S. Greco, M. Nicotra, M. Romano, and C. E. Schillaci, "Evaluating and comparing entrepreneurial ecosystems using SMAA and SMAA-S," J. Technol. Transf., pp. 1-35, 2018.

[59] M. D. McKay, R. J. Beckman, and W. J. Conover, "Comparison of three methods for selecting values of input variables in the analysis of output from a computer code," Technometrics, vol. 21, no. 2, pp. 239-245, 1979.

[60] D. E. Grierson, "Pareto multi-criteria decision making," Adv. Eng. Inform., vol. 22, no. 3, pp. 371-384, 2008.

[61] I. Laory, N. B. Hadj Ali, T. N. Trinh, and I. F. Smith, "Measurement system configuration for damage identification of continuously monitored structures," J. Bridge Eng., vol. 17, no. 6, pp. 857-866, 2012. 